\title{
OS SONS FRICATIVOS NO POLONÊS FALADO NO MUNICÍPIO DE CRUZ MACHADO, NO PARANÁ
}

\author{
Fricative Sounds in Polish Spoken in the Municipality of Cruz Machado, \\ Paraná
}

\author{
Sônia Eliane NIEWIADOMSKI \\ Universidade Estadual do Centro-Oeste \\ soniaeliane@gmail.com \\ http://orcid.org/0000-0002-7560-5763 \\ Luciane Trennephol da COSTA \\ Universidade Estadual do Centro-Oeste \\ 1tcosta@unicentro.br \\ http://orcid.org/0000-0002-0223-7787
}

\begin{abstract}
RESUMO: O presente trabalho objetiva analisar acusticamente as fricativas [z.s $\int 36$ z $]$ do polonês falado na comunidade do Rio do Banho, Cruz Machado-PR. Mesmo com o passar do tempo, a tradição da língua trazida pelos seus antepassados, cujo sistema se modificou na longínqua pátria, ainda se mantém fortemente nas comunidades interioranas de ascendência polonesa no Paraná. O presente estudo é descritivo, baseando-se na Teoria Acústica de Produção de Fala (KENT; READ, 1992). Investigamos os dados de fala de oito informantes, registrados por meio de um gravador digital e microfone unidirecional acoplado, sendo quatro homens e quatro mulheres, divididos em duas faixas etárias: até 60 anos e acima de 60 anos, por meio do protocolo de leitura de fraseveículo (palavras inseridas na frase-veículo POWIEDZ PREDKO - em português Fale ___ rápido). A descrição dos dados é por meio da análise acústica, com o software Praat (BOERSMA; WEENINK, 2016). Os resultados apontam que os sons fricativos, analisados por meio das pistas acústicas de valor da frequência do início do ruído e valor dos formantes na vogal subsequente, apresentam variabilidade de realização dos dados pelos informantes e entre os informantes e evidências de presença de articulação retroflexa nos sons fricativos. PALAVRAS-CHAVE: Fricativas; Análise acústica; Polonês; Língua de imigração.
\end{abstract}

ABSTRACT: The present work aims to analyze acoustically the spoken polish fricatives [z.S $\int 36$ z] in the Rio do Banho community, Cruz Machado-PR. Even with the after many years, the tradition of the language brought by its ancestors, whose system has changed in the 
distant homeland, still strongly remains in the countryside communities of Polish descendants in Paraná. The present study is descriptive, based on the Acoustic Theory of Speech Production (KENT; READ, 1992). We investigated the speech data of eight informants, recorded through a digital recorder and an unidirectional microphone, four men and four women, sorted into two age groups: up to 60 years and over 60 years, using the protocol of reading a vehicle phrase (words inserted in the vehicle phrase POWIEDZ PREDDKO - in English Speak fast). The data description is done by acoustic analysis, with the Software Praat (BOERSMA; WEENINK, 2016). The results indicate that the fricative sounds, analyzed through the acoustic tracks of frequency value of the beginning of the noise and the formants value on the next vowel, show variability of data performance by the informants and between them and evidences of presence of retroflex articulation in fricatives sounds. KEYWORDS: Fricatives; Acoustic analysis; Polish; Immigration language.

STRESZCZENIE: Niniejszy artykuł ma celu analizę akustyczną spółgłosek frykatywnych [z, S $\int 36$ z $]$ w języku polskim mówionym w społeczności Rio do Banho, Cruz Machado-PR. Mimo upływu wielu lat przywieziona przez przodków tradycja językowa, której system zmieniał się w dalekiej ojczyźnie, wciąż pozostaje silnie zakorzeniona w społecznościach polskich potomków w głębi stanu Paraná. Niniejsze badania mają charakter opisowy i opierają się na akustycznej teorii produkcji mowy (KENT; READ, 1992). Zbadano dane mowy ośmiu informatorów, nagrane za pomocą cyfrowego rejestratora i sprzężonego mikrofonu jednokierunkowego. Badani to czterej mężczyźni i cztery kobiety podzieleni na dwie grupy wiekowe: do 60 lat i powyżej 60 lat. Badanie przeprowadzono za pomocą odczytu zdania POWIEDZ PRȨDKO ze wstawionymi różnymi słowami. Opis mowy jest oparty na analizie akustycznej przy pomocy oprogramowania Praat (BOERSMA; WEENINK, 2016). Wyniki wskazują, że dźwięki frykatywne, analizowane za pomocą ścieżki akustycznej wartości częstotliwości początku szumu i wartości formantów w kolejnej samogłosce, przedstawiają zmienność/wariancję w wykonywaniu danych przez informatorów jak i wśród informatorów oraz świadczą o obecności artykulacji z retrofleksją w dźwiękach frykatywnych. SŁOWA KLUCZOWE: Spółgłoski frykatywne; Analiza akustyczna; Polski; Język imigracji. 


\section{INTRODUÇÃO}

As fricativas são uma das classes de sons mais produtivas nas línguas humanas de acordo com o IPA e também na língua polonesa. No entanto, há poucos estudos que abrangem as fricativas na língua polonesa, podemos citar dentre eles: Hauser (2019), Colling (2014), Zygis; Hamann (2003), Padgett; Zygis (2007) Halle; Stevens (1997), Dogil (1990), Kudela (1968).

Nosso trabalho objetiva descrever acusticamente as fricativas [z, s $\left.\int \begin{array}{lll}3 & \text { z }\end{array}\right] \mathrm{da}$ língua polonesa falada no Brasil, mais especificamente na cidade de Cruz Machado no interior do Paraná. Há mais de um século, a língua polonesa mantém sua vitalidade nesse município, majoritariamente na modalidade oral, sendo a língua materna de muitos indivíduos de ascendência polonesa. Entretanto, não há estudos descritivos acerca das fricativas nesta localidade e em outras comunidades de ascendência polonesa no Brasil. Desta forma, a nossa pesquisa pretende contribuir para preencher essa lacuna, ampliar e ajudar no conhecimento da realidade linguística do Paraná, visando a descrição de alguns sons fricativos do polonês.

Cruz Machado é um município grande em extensão territorial, cerca de 1.477 quilômetros quadrados, localizado na região sudeste do estado do Paraná, aproximadamente há $300 \mathrm{~km}$ da capital Curitiba. Foi um dos núcleos de colonização polonesa no estado. De acordo com Orzeł-Dereń (2014), em 19 de dezembro de 1910, por ordem do governo federal, o Serviço de Povoamento do Solo fundou o núcleo colonial Cruz Machado. Em julho de 1911, estabeleceram-se naquela localidade (hoje conhecida como Pátio Velho) os primeiros colonizadores poloneses, provenientes sobretudo da região de Lubelszczyzna (região sudeste da Polônia, ocupada pela Rússia), das cidades de Siedlce, Lublin, Chełm e Białystok.

Há mais de um século, portanto, a língua polonesa é falada no interior do Paraná e neste texto apresentamos um recorte específico, parte da investigação empreendida em (NIEWIADOMSKI, 2019), abordando alguns sons fricativos. Iniciamos tratando da descrição articulatória e acústica dos sons fricativos. Na sequência, apresentamos a metodologia do estudo, discutimos os dados e tecemos nossas considerações finais. 


\section{CARACTERIZAÇÃO ARTICULATÓRIA E ACÚSTICA DAS FRICATIVAS}

O sistema consonantal do polonês, segundo Gussmann (2007), apresenta: a) oclusivas bilabiais $[\mathrm{p}, \mathrm{b}]$, dentais $[\mathrm{t}, \mathrm{d}]$, velares $[\mathrm{k}, \mathrm{g}]$, palatais velares $[\mathrm{c}, \mathrm{f}]$; b) nasal bilabial [m], dental [n], palatal [n], velar [n]; c) lateral alveolar [1]; d) vibrante alveolar [r]. Há ainda as fricativas e africadas, para as quais, a língua polonesa possui uma especificação mais detalhada quanto ao ponto de articulação do que o português brasileiro. Desse modo, para as fricativas, o polonês apresenta labiodentais [f, v], dentais $[\mathrm{s}, \mathrm{z}]$, alvéolo-palatais $[6$, z], pós-alveolares $\left[\int, 3\right]$ e velar [x]. Para as africadas, apresenta dentais [ts, dz], alvéolopalatais [t6, dz] e pós-alveolares [t $\int$, dz] (GUSSMANN, 2007, p. 5-6).

Destacamos que há divergências entre alguns autores, como entre Gussmann (2007), Jassem (2003) e Padgett e Zygis (2007), em relação aos sons consonantais do polonês, no que diz respeito, principalmente, ao uso de símbolos fonéticos e discriminação de sons diferentes, conforme a figura 1 e figura 2.

FIGURA 1 - SISTEMA CONSONANTAL DO POLONÊS

\begin{tabular}{|c|c|c|c|c|c|c|c|}
\hline & Labial & Alveolar & Alveopalatal & Retroflex & Palatal & Velar & Glottal \\
\hline Stop & $\mathrm{p} \mathrm{b}$ & $\mathrm{t} \mathrm{d}$ & & & & $\mathrm{kg}$ & \\
\hline Fricative & $\mathrm{f} \mathrm{v}$ & $\mathrm{s} \mathrm{z}$ & $6 \mathrm{z}$ & $\mathrm{S} \mathrm{z}$ & & $\mathrm{x}$ & $\mathrm{h}$ \\
\hline Affricative & & $\mathrm{ts} \mathrm{dz}$ & $\mathrm{t} 6 \mathrm{dz}$ & $\mathrm{ts} \mathrm{dz}$ & & & \\
\hline Nasal & $\mathrm{m}$ & $\mathrm{n}$ & & & $\mathrm{n}$ & & \\
\hline Approximant & & $\mathrm{l} \mathrm{I}$ & & & $\mathrm{j}$ & $\mathrm{w}$ & \\
\hline
\end{tabular}

FONTE: PADGETT; ZYGIS, 2007, p. 293. 
FIGURA 2 - SONS CONSONANTAIS DA LÍNGUA POLONESA

\begin{tabular}{|c|c|c|c|c|c|c|c|}
\hline & Labial & Labiodental & $\begin{array}{l}\text { (Post) } \\
\text { dental }\end{array}$ & Alveolar & $\begin{array}{c}\text { Alveolo- } \\
\text { palatal }\end{array}$ & Palatal & Velar \\
\hline Plosive & $\mathrm{pb}$ & & $\mathrm{td}$ & & & $c_{J}$ & $\mathrm{~kg}$ \\
\hline Fricative & & $\mathrm{fv}$ & $\mathrm{s} \mathrm{z}$ & $\int 3$ & 67 & & $\mathrm{x}$ \\
\hline Affricative & & & ts $d z$ & $t \int d_{3}$ & t6 $d 7$ & & \\
\hline Nasal & $\mathrm{m}$ & & $\mathrm{n}$ & & $\mathrm{n}$ & & $\eta$ \\
\hline Lateral & & & 1 & & & & \\
\hline \multirow[t]{2}{*}{ Flap/Trill } & & & & $\mathrm{r}$ & & & \\
\hline & \multicolumn{3}{|c|}{ Front } & \multicolumn{4}{|c|}{ Back } \\
\hline Approximant & \multicolumn{3}{|c|}{$\mathrm{j}(\hat{\mathrm{j}})$} & \multicolumn{4}{|c|}{$\mathrm{w}(\hat{\mathrm{w}})$} \\
\hline
\end{tabular}

FONTE: JASSEM, 2003, p.103.

Nesta pesquisa, empregamos os símbolos do Alfabeto Fonético Internacional (IPA) e, no quadro 1, apresentamos as fricativas e as africadas de acordo com as informações extraídas de Gussmann (2007).

QUADRO 1 - FRICATIVAS E AFRICADAS NO POLONÊS

\begin{tabular}{|c|cc|cc|cc|cc|c|}
\hline Ponto & Labiodentais & Dentais & \multicolumn{2}{|c|}{$\begin{array}{c}\text { Alvéolo- } \\
\text { palatais }\end{array}$} & \multicolumn{2}{|c|}{$\begin{array}{c}\text { Pós- } \\
\text { alveolares }\end{array}$} & Velar \\
\hline Africada & & & ts & $\mathrm{dz}$ & $\mathrm{t} 6$ & $\mathrm{~d} z$ & $\mathrm{t} \int$ & $\mathrm{d} 3$ & \\
\hline Fricativa & $\mathrm{f}$ & $\mathrm{v}$ & $\mathrm{s}$ & $\mathrm{z}$ & 6 & $\mathrm{z}$ & $\int$ & 3 & $\mathrm{X}$ \\
\hline
\end{tabular}

FONTE: Adaptado conforme informações de GUSSMANN, 2007, p. 5-6.

A divergência da classificação de pontos entre os teóricos para os sons fricativos do polonês deve-se aos desafios que essa classe representa. De acordo com Kent e Read (2015), as fricativas são produzidas a partir da fonte de ruído, resultante da turbulência 
de ar gerada pela constrição por uma condição de turbulência em algum ponto do trato vocal. $\mathrm{O}$ ar que passa por essa contrição gera um ruído turbulento, de modo que o ruído é a fonte de energia para a produção do som (p. 38). A turbulência é a fonte de energia acústica para vários sons da fala inclusive para as fricativas (KENT; READ, 2015). Na figura 3, visualizamos o modelo de produção de ruído para as fricativas.

\section{FIGURA 3 - MODELO DE PRODUÇÃO DO RUÍDO TURBULENTO PARA AS FRICATIVAS}

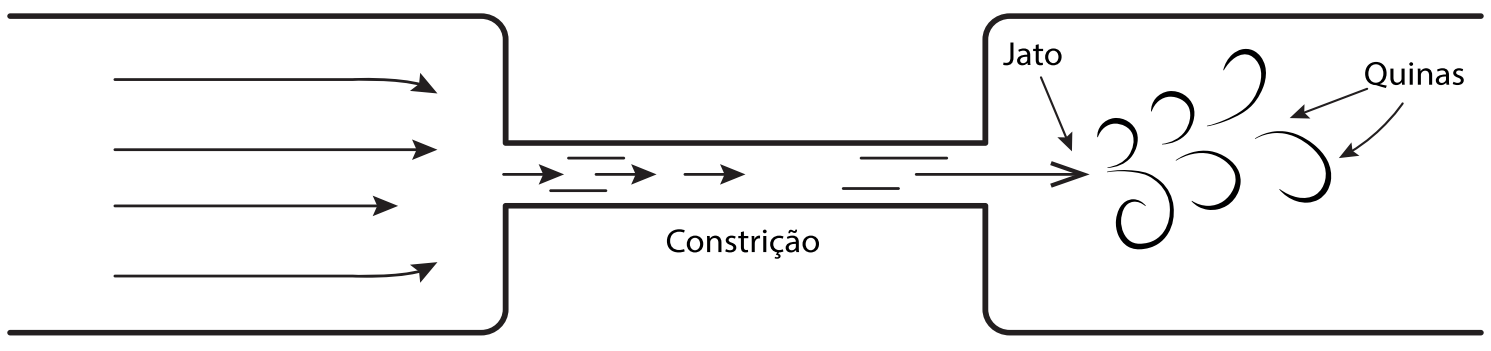

FONTE: KENT; READ, 2015, p. 74.

Para produzir uma fricativa se exige um maior grau de precisão articulatória do que para realizar sons oclusivos e nasais (LADEFOGED; MADDIESON, 1996). Ladefoged e Johnson (2011) reiteram que as fricativas são distintivas entre elas por conta dos diferentes gestos articulatórios. Podemos caracterizá-las conforme o vozeamento e ponto de articulação, isto é, as fricativas podem ser surdas (ausência da vibração das pregas vocais) ou sonoras (vibração das pregas vocais). Além disso, podemos identificálas quanto à quantidade de concentração de energia do ruído. Sendo assim, as fricativas são sibilantes (estridente) ou não sibilantes (não estridente), no caso, as sibilantes apresentam uma energia acústica de maior intensidade.

O ponto de articulação de uma fricativa é dado pelo local do trato vocal, no qual ocorre a constrição. Ao produzir um segmento fricativo, é preciso que o ar passe por uma constrição estreita no trato vocal, gerando turbulência (BARBOSA; MADUREIRA, 2015).

Desta forma, as fricativas são definidas pela: (a) formação de uma constrição estreita em algum ponto do trato vocal; (b) desenvolvimento de fluxo aéreo turbulento e (c) geração de ruído de turbulência. O que pode ainda distinguir as fricativas, como uma categoria de som, são as durações longas de ruído, que consistem num intervalo extenso de energia aperiódica. 
Kent e Read (2015) reiteram que as propriedades acústicas estão associadas a gestos articulatórios distintivos, assim para as fricativas:

\begin{abstract}
Vários candidatos podem ser considerados, incluindo momentos espectrais específicos (Behrens; Blumstein, 1988a), pico espectral (Jongman et al., 2000) e medidas de inclinação espectral (Evers et al., 1998). Um eventualmente pode emergir como a característica preferida para todas as línguas em que o contraste é relevante. Entretanto, no momento, pode-se dizer que [s], comparado a [S], tende a ter um pico espectral de frequência mais alta, maior assimetria (mas não uniformemente em todos os estudos), mais energia na região de frequência de 3,5-5,0 kHz (em oposição à região de frequência 2,5-3,5 $\mathrm{kHz}$ ) e uma inclinação mais rasa para o envelope espectral abaixo de 2,5 kHz (KENT; READ, 2015, p. 270).
\end{abstract}

As fricativas são aperiódicas, ou seja, ruidosas, com energias concentradas em faixas mais altas, entre 3000 e $10000 \mathrm{~Hz}$ (SHADLE, 1985). Portanto, uma caraterística que distingue as fricativas entre si, segundo Silva (2007), por exemplo, [s] e [J], é a região de frequência onde começa o ruído fricativo. Para o som fricativo [s], a fricção inicia por volta dos $4000 \mathrm{~Hz}$, ao passo que para a fricativa [J] a fricção começa em torno de 3000 $\mathrm{Hz}$, sendo assim é mais baixa para a pós-alveolar. Já na fricativa labiodental [f], a energia de produção inicia numa região ainda mais baixa se espalhando por todo o espectrograma.

Para Barbosa e Madureira (2015), as fricativas apresentam distribuição de energia do ruído na forma de níveis variados de cinza em diferentes faixas espectrais - nas labiodentais [f, v], encontra-se um nível aproximadamente regularmente distribuído; nas alveolares [s, z], verifica-se uma concentração em faixa de frequência de aproximadamente $4000 \mathrm{~Hz}$; já nas pós-alveolares, começa em $2000 \mathrm{~Hz}$.

Apesar de as características articulatórias serem similares, existem diferenças acústicas entre as línguas, por exemplo, na língua inglesa, o espectro da fricativa [ $]$ ] começa com uma concentração de energia na faixa de frequência de 2000-3000 Hz. Já para a fricativa [s], começa em torno de 3560-4400 Hz (STEVENS; KLATT, 1968).

Ladefoged e Disner (2012) apresentam um espectrograma com as frequências das fricativas: dental [s], pós-alveolar [s] e a fricativa alvéolo-palatal [6]. Notamos, na figura 4, que a concentração de energia acústica para a fricativa [s] é visível acima dos 3000

\footnotetext{
${ }^{1}$ Em nosso estudo, utilizamos, para a pós-alveolar, o símbolo [S], conforme apresentado no IPA (Alfabeto Fonético Internacional).
} 
Hz. Ao passo que, para a fricativa pós-alveolar, um pouco abaixo de $2000 \mathrm{~Hz}$. Já para a alvéolo-palatal, um pouco acima de $2000 \mathrm{~Hz}$.

\section{FIGURA 4 - ESPECTROGRAMA DAS FRICATIVAS NO POLONÊS}

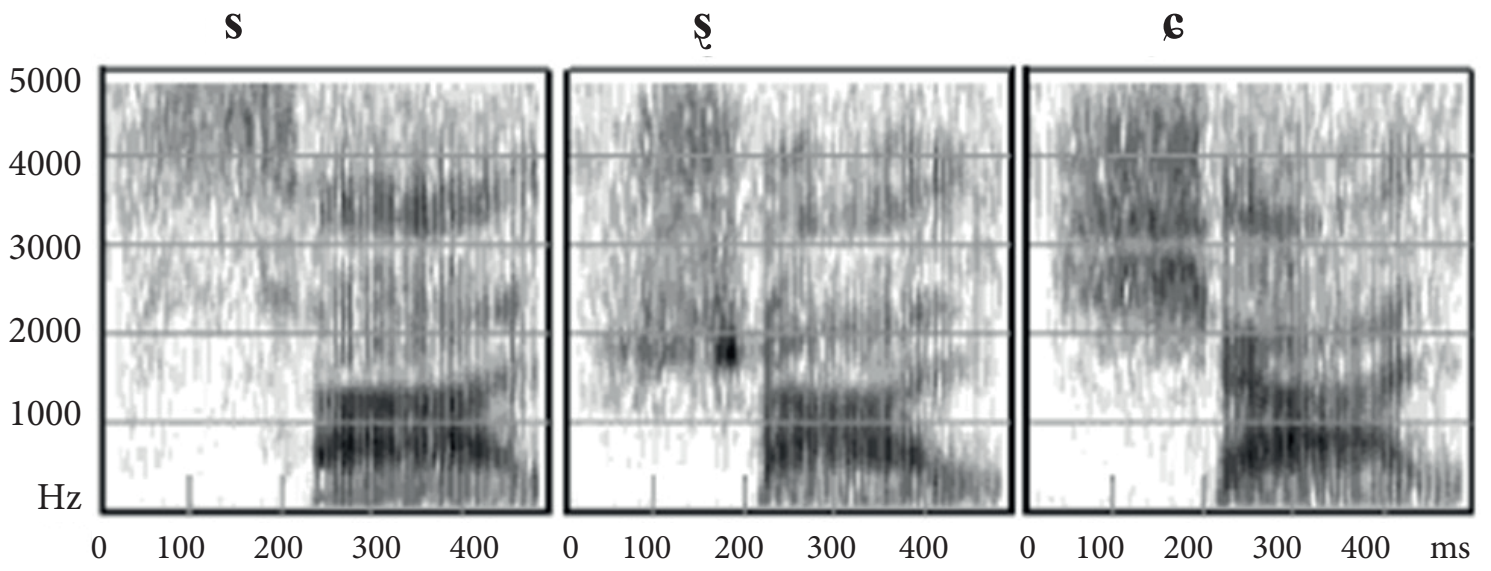

FONTE: LADEFOGED; DISNER, 2012, p. 170.

Para Jesus (1999), em relação às fricativas, o contexto vocálico tem uma influência fundamental nas propriedades acústicas. Sendo assim, as vogais aparentemente influenciam no pico espectral das fricativas adjacentes. $\mathrm{O}$ autor, em suas pesquisas, chega à conclusão de que:

O pico do espectro do/s/ em início de palavra em contexto /o/ é $1 \mathrm{kHz}$ mais baixo em relação ao pico no espectro de um $/ \mathrm{s} / \mathrm{em}$ contextos de /i/, /it e /e/. O pico do /z/ em início de palavra é $1,5 \mathrm{kHz}$ mais baixo em contextos vocálicos /o/ e /o/, e $500 \mathrm{~Hz}$ mais baixo quando seguido de /u/, em relação ao pico do espectro de /z/ no contexto vocálico de /i/ e /e/. O espectro do / $/ 3 /$ em início de palavra seguido de $/ \varepsilon /$ tem seu pico na faixa dos $4 \mathrm{kHz}$, com amplitude mais alta que o mesmo pico nos contextos de /o/, /o/ e /u/ (JESUS, 1999 apud HAUPT, 2007, p. 38).

Como podemos perceber, as fricativas são uma classe de sons muito complexa. Isto posto, autores, como Ladefoged e Maddieson (1996) e Hamann (2004), caracterizaram as fricativas pós-alveolares no polonês como retroflexas. Assim, a título de exemplo, a classificação do som no polonês em relação à retroflexão não é tão clara, e menos ainda os critérios para sua classificação. No que diz respeito às consoantes retroflexas, Trask (1996) descreve como sons articulados com a ponta da língua dobrada/inclinada para trás e o ponto de articulação pós-alveolar. Entretanto, essa definição não se aplica para 
todas as línguas. No caso das fricativas pós-alveolares vozeadas e desvozeadas na língua polonesa, pesquisadores as descrevem como articuladas sem envolvimento ativo da ponta da língua na constrição e com o corpo de língua plana (HAMANN, 2002).

Dado isso, Hamann (2002) esclarece que os segmentos retroflexos apresentam variação articulatória em relação ao articulador (ou seja, de apical ou subapical à laminal) e ao ponto da articulação (isto é, do alveolar ao palatal). Por conta dessa variação, é mais complexo encontrar propriedades articulatórias comuns que sejam válidas para todas as instâncias de retroflexão.

Ainda em relação à complexidade dos segmentos retroflexos no polonês, Keating (1991) argumenta que há uma impressão acústica semelhante à de outros retroflexos, sendo assim, pode ser incluído na classe de sons retroflexos. Mas aqui novamente percebemos que a pesquisadora também não fornece nenhum critério articulatório.

Colling (2014, p. 15) chama a atenção para o fato de que, no polonês, os sons fricativos pós-alveolares se distinguem por "justamente a colocação do dorso da língua em posição mais ou menos próxima do palato". Contudo no inglês a língua é levemente elevada atrás do ponto de constrição (LADEFOGED; MADDIESON, 1996).

Hamann (2004) reitera que as fricativas pós-alveolares são referidas por alguns pesquisadores (DŁUSKA, 1950; GUSSMANN, 1980; WIERZCHOWSKA, 1980; RUBACH, 1984, apud HAMANN, 2004) como os seguintes símbolos /̌̌/ e /ž/. Entretanto, outros autores (BIEDRZYCKI, 1974; DOGIL, 1990; JASSEM, 2003, apud HAMANN, 2004) utilizam os símbolos fonéticos do IPA [S] e [3], respectivamente. No entanto, as fricativas pós-alveolares [S] e [3] "se diferem significativamente em inglês, são claramente laminares, enquanto os fonemas poloneses parecem ter o ápice envolvido em sua articulação" (HAMANN, 2004, p. 53), vindo daí sua caracterização como retroflexas.

$\mathrm{Na}$ análise acústica, as pós-alveolares podem ser distinguidas das retroflexas. Para tanto, no espectrograma, observamos que, nas fricativas retroflexas, normalmente o ruído de fricção é menor, e ainda verificamos que há uma grande concentração de energia do segundo e terceiro formante das vogais adjacentes, em torno de $1600 \mathrm{~Hz}$ e $2400 \mathrm{~Hz}$ (HAMANN, 2004, p. 57). Características semelhantes, no que diz respeito às fricativas retroflexas, foram observadas por Stevens (1998). As fricativas [J] e [3] no inglês mostram, no espectrograma, um ruído intenso na região de 2000-7000 Hz. Isso quer dizer que esses valores são superiores em relação às retroflexas, cuja frequência é visível em torno de $1800 \mathrm{~Hz}$ para o segundo formante e $2600 \mathrm{~Hz}$ para o terceiro formante (STEVENS, 1998, p. 410-411). 
Diante disso, Hamann (2004) conclui que as fricativas pós-alveolares, tanto no polonês quanto no russo, deveriam ser representadas pelos seguintes símbolos fonéticos do IPA [s, z], pois mostram-se mais semelhantes às fricativas retroflexas do que às fricativas pós-alveolares do inglês. As fricativas alvéolo-palatais e retroflexas no polonês estão em distribuição complementar, isto é, há uma restrição fonotática que não permite certas sequências de segmentos. Ainda segundo Hamann (2004) no ambiente em que ocorre a retroflexa, adjacente à vogal centralizada, não ocorre as alvéolos-palatais.

Já Halle e Stevens (1997) indicam que as fricativas desvozeadas se distinguem pela presença ou ausência de um pico espectral na região F2 do espectro de ruído fricativo. O ruído da fricção para as fricativas alvéolo-palatal é visível entre 2500 - 3500 Hz (LADEFOGED; DISNER, 2012).

Dada a complexidade das fricativas, Halle e Stevens (1997) apontam que no IPA há uma coluna especial para essas consoantes, localizada entre as colunas para fricativas palato-alveolar e palatal, assim esses segmentos têm um ponto de articulação próprio, distintivo das demais fricativas. Os autores destacam que estudos acerca dessas fricativas foram abordados por Ladefoged e Maddieson (1996) caracterizando esses segmentos como fricativas pós-alveolares palatalizadas, contrastando-os com as fricativas retroflexas. Para os autores, a diferença entre elas se deve à presença ou ausência de uma articulação suplementar do corpo da língua.

Para descrever acusticamente o ponto de articulação das fricativas, classe de consoantes bastante produtiva na língua polonesa, no polonês falado em Cruz Machado, levaremos em conta a concentração de energia do pico espectral. Tomando como base Barbosa; Madureira (2015), Kent; Read (2015), Gussmann (2007), Padgett; Zygis, 2007 e Silva (2007), iremos diferenciar o ponto de articulação das fricativas pelo início de concentração de energia no espectro. Adicionalmente, analisaremos a presença de retroflexão, seguindo Hamann (2004) e Ladefoged e Disner (2012), observando os valores dos formantes vocálicos do som da vogal adjacente ao som fricativo.

\section{METODOLOGIA}

Para descrever os sons fricativos, mais especificamente [z, S $\int 36$ z 3 , embasamonos na Teoria Acústica da Produção da Fala, também conhecida como Teoria Fonte-Filtro, proposta por Fant (1970) com o objetivo principal de relacionar propriedades acústicas a correlatos articulatórios na produção da fala. Investigando as configurações acústicas dos sons, de acordo com as diferentes manobras articulatórias de suas produções, 
estabelecem-se correspondências entre detalhes fonéticos de produção e de configuração acústica observadas por meio da análise acústica, possibilitando o exame de detalhes fonéticos da produção dos sons.

O corpus desta pesquisa abarca gravação de dados de fala em língua polonesa de indivíduos com ascendência polonesa do município de Cruz Machado, mais especificamente da comunidade do Rio do Banho, constituindo assim uma amostra do Banco de Dados do Laboratório de Fonética do Núcleo de Estudos Eslavos da Universidade Estadual do Centro-Oeste. A amostra deste trabalho é constituída por gravação de oito informantes, sendo quatro do sexo feminino e quatro do sexo masculino, divididos em duas faixas etárias: até 60 anos e acima de 60 anos. Todos os informantes têm o polonês como primeira língua, falam-no e entendem-no, e três participantes também sabem ler e escrever em polonês. Utilizamos, como estímulo, a leitura de frase veículo para a coleta de dados que continha as fricativas. Nesse protocolo, mostramos uma lista de palavras em português, apresentados por meio de slides, as quais os informantes deveriam produzir em polonês, inseridas na seguinte frase veículo² $P O W I E D Z$ PRȨDKO (em português: fale ___ rápido), da qual foram posteriormente recortados os sons para análise.

Gravamos quatro repetições para cada informante, isto é, cada palavra foi produzida quatro vezes por cada um dos oito participantes. O uso das palavras na frase veículo uniformiza suas realizações, atenuando os efeitos prosódicos e coarticulatórios entre as fronteiras de palavra.

O quadro 2 apresenta as informações detalhadas de todos os informantes da pesquisa.

\section{QUADRO 2 - PERFIL DOS INFORMANTES.}

\begin{tabular}{|c|c|c|c|c|c|c|}
\hline \multicolumn{2}{|c|}{ Informantes } \\
\hline $\begin{array}{c}\text { Número do } \\
\text { informante }\end{array}$ & Sexo & Idade & Profissão & Escolaridade & $\mathbf{1}^{\mathbf{0}}$ língua & $\begin{array}{c}\text { Grau de } \\
\text { conhecimento } \\
\text { do polonês }\end{array}$ \\
\hline 1. & $\mathrm{~F}$ & $\begin{array}{c}26 \\
\text { anos }\end{array}$ & $\begin{array}{c}\text { Dona de } \\
\text { casa }\end{array}$ & $\begin{array}{c}\text { Ens. } \\
\text { Fundamental }\end{array}$ & Polonês & Entende e fala \\
\hline 2. & $\mathrm{~F}$ & $\begin{array}{c}37 \\
\text { anos }\end{array}$ & $\begin{array}{c}\text { Dona de } \\
\text { casa }\end{array}$ & $\begin{array}{c}\text { Ens. } \\
\text { Fundamental } \\
\text { incompleto }\end{array}$ & Polonês & Entende e fala \\
\hline
\end{tabular}

\footnotetext{
${ }^{2}$ Frases veículo são recursos usados durante a gravação dos dados de fala, principalmente de palavras- alvo de forma isolada, por exemplo: "Diga baixinho".
} 


\begin{tabular}{|c|c|c|l|c|l|l|}
\hline 3. & $\mathrm{M}$ & $\begin{array}{c}39 \\
\text { anos }\end{array}$ & Agricultor & $\begin{array}{c}\text { Ens. } \\
\text { Fundamental }\end{array}$ & Polonês & Entende e fala \\
\hline 4. & $\mathrm{M}$ & $\begin{array}{c}39 \\
\text { anos }\end{array}$ & Agricultor & $\begin{array}{c}\text { Ens. } \\
\text { Fundamental } \\
\text { incompleto }\end{array}$ & Polonês & Entende e fala \\
\hline 5. & $\mathrm{M}$ & $\begin{array}{c}61 \\
\text { anos }\end{array}$ & Agricultor & $\begin{array}{c}\text { Primário } \\
\text { completo }\end{array}$ & Polonês & Entende e fala \\
\hline 6 & $\mathrm{~F}$ & $\begin{array}{c}64 \\
\text { anos }\end{array}$ & Aposentada & $\begin{array}{c}\text { Primário } \\
\text { completo }\end{array}$ & Polonês & $\begin{array}{c}\text { Entende, fala, } \\
\text { escreve e lê }\end{array}$ \\
\hline 7. & $\mathrm{M}$ & $\begin{array}{c}70 \\
\text { anos }\end{array}$ & Aposentado & $\begin{array}{c}\text { Primário } \\
\text { completo }\end{array}$ & Polonês & $\begin{array}{c}\text { Entende, fala, } \\
\text { escreve e lê }\end{array}$ \\
\hline 8. & $\mathrm{~F}$ & $\begin{array}{c}89 \\
\text { anos }\end{array}$ & Aposentada & $\begin{array}{c}\text { Primário } \\
\text { completo }\end{array}$ & Polonês & $\begin{array}{c}\text { Entende, fala, } \\
\text { escreve e lê }\end{array}$ \\
\hline
\end{tabular}

FONTE: Elaborado pelas autoras.

Já o quadro 3 apresenta os dados de sons fricativos analisados acusticamente com a escrita formal em polonês e o significado em português, bem como, entre colchetes, a transcrição fonética de acordo com o dicionário Polaco-Português da Editora Porto (DŁUGOSZ, 2000).

A gravação dos dados foi registrada por meio de gravador digital e microfone unidirecional acoplado, nas residências dos informantes, localizadas na comunidade do Rio do Banho em local reservado e tentando atenuar o máximo possível os ruídos externos, preservando a qualidade dos registros dos dados de fala, sem interferência.

\section{QUADRO 3 - PALAVRAS COM SONS FRICATIVOS}

\begin{tabular}{|c|c|c|}
\hline Português & Polonês & Transcrição fonética \\
\hline Rio & Rzeka & ['3cka] \\
\hline Vida & $\dot{Z} y c i e$ & ['3itçع] \\
\hline Sapo & $\dot{Z} a b a$ & ['zaba] \\
\hline Escola & Szkoła & ['Jkowa] \\
\hline Vidro & Szkto & ['Jkwo] \\
\hline Seis & Sześć & 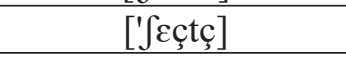 \\
\hline Verde & Zielony & [zéloni] \\
\hline Nata & Śmietana & [çm, $\left.\varepsilon^{\prime} \operatorname{tana}\right]$ \\
\hline Mundo & Świat & ['çf,jat] \\
\hline
\end{tabular}

FONTE: Elaborado pelas autoras, com transcrição fonética de Długosz (2000). 
Para fins da análise, cada dado de fala foi editado separadamente e analisado acusticamente com o apoio do programa Praat (BOERSMA; WEENINK, 2016).

\section{ANÁLISE DOS DADOS E RESULTADOS}

Nesta etapa, apresentamos os resultados da análise acústica realizada. A pista acústica observada para a identificação das consoantes foi o início da faixa de frequência do ruído das fricativas, todas em posição de ataque silábico, e os valores dos três primeiros formantes das vogais subsequentes para o ponto de articulação. Apesar de os falantes femininos apresentaram valores em frequência mais altos do que os valores apresentados pelos informantes masculinos, como se esperaria, em função das diferenças de frequência fundamental, não fizemos a separação dos resultados por sexo. Foi possível, no entanto, observar a variação nas frequências apresentadas para ambos os sexos. Para que se pudesse visualizar mais claramente essa variação, nas tabelas, apresentamos primeiramente os resultados concernentes aos informantes femininos (1, 26 e 8) e, na sequência, aos informantes masculinos $(3,4,5$ e 7$)$.

Nas transcrições fonéticas, seguimos a maioria dos autores pesquisados, como Gussmann (2007) e Ladefoged e Disner (2012), e consideramos a presença das fricativas alveolo-palatais com retroflexão.

As descrições e análises dos sons fricativos serão demonstrados por meio de tabelas com os valores absolutos dos dados $^{3}$, sem contabilizar a média de valores por conta das variabilidades nos dados dos informantes para o início da frequência do ruído. As variações constatadas se referem ao valor do início da frequência de ruído dos sons fricativos, desta forma, distinguindo o ponto de articulação entre eles. Já para a transição dos formantes (F1, F2 e F3) entre a fricativa e a vogal seguinte, apresentamos a média dos valores.

Vejamos a tabela 1, com informações quanto à produção da pós-alveolar vozeada nos dados de $r z e k a$ ['3cka] , pelos oito informantes nas quatro repetições. Nessa produção, verificamos uma variabilidade entre os falantes. Nas realizações dos Informantes 1, 2, 3,

\footnotetext{
${ }^{3}$ Apesar de não analisamos em separado os resultados concernentes aos participantes femininos e masculinos, porque observamos que os valores mais baixos ou mais altos não eram coerentes com o sexo (ou seja, valores mais altos para o feminino e mais baixos para o masculino). Havia uma variação que pareceu independer do sexo do informante.

${ }^{4}$ Transcrição fonética de acordo com o dicionário Polaco-Português da Editora Porto (DŁUGOSZ, 2000).
} 
4 e 8 , constatamos que o início da frequência do ruído está acima de $2000 \mathrm{~Hz}$, enquanto, para os participantes, 5, 6 e 7, na maioria foi computado abaixo de $2000 \mathrm{~Hz}$.

Nas descrições de Ladefoged e Disner (2012), o ruído da frequência da fricativa caracterizada como retroflexa no polonês começa um pouco abaixo de $2000 \mathrm{~Hz}$. Já nas descrições de Hamann (2004) e Stevens (1998), as fricativas retroflexas possuem uma concentração de energia bem mais baixa no espectrograma do que as fricativas pósalveolares, em torno de $1600 \mathrm{~Hz}$ ou $1800 \mathrm{~Hz}$, respectivamente, para o segundo formante das vogais adjacentes. Nesse sentido, podemos hipotetizar que os Informantes 5, 6 e 7 produziram uma fricativa retroflexa. Ao passo que os Informantes 1, 2, 3, 4 e 8 produziram fricativa semelhante à pós-alveolar do inglês e português. Outra observação relevante constatada se refere à sonoridade, algumas das produções apresentam características de surdas, pois, no espectrograma, é possível observar a sonoridade da fricativa por conta da presença/ausência da barra de sonoridade. Como, na figura 4, não há essa barra de sonoridade, fica evidenciada uma fricativa não vozeada.

\section{TABELA 1 - VALORES DO COMEÇO DA FREQUÊNCIA DE RUÍDO NOS DADOS DE RZEKA ['3عka]}

\begin{tabular}{ccccc}
\hline Inf. & Repetição 1 & Repetição 2 & Repetição 3 & Repetição 4 \\
\hline 1 & $2722 \mathrm{~Hz}$ & $2407 \mathrm{~Hz}$ & $2372 \mathrm{~Hz}$ & $2512 \mathrm{~Hz}$ \\
2 & $2652 \mathrm{~Hz}$ & $2547 \mathrm{~Hz}$ & $2477 \mathrm{~Hz}$ & $2022 \mathrm{~Hz}$ \\
6 & $1741 \mathrm{~Hz}$ & $1776 \mathrm{~Hz}$ & $1636 \mathrm{~Hz}$ & $1741 \mathrm{~Hz}$ \\
8 & $2267 \mathrm{~Hz}$ & $2442 \mathrm{~Hz}$ & $2512 \mathrm{~Hz}$ & $2442 \mathrm{~Hz}$ \\
\hline 3 & $2652 \mathrm{~Hz}$ & $2302 \mathrm{~Hz}$ & $2302 \mathrm{~Hz}$ & $2162 \mathrm{~Hz}$ \\
4 & $2092 \mathrm{~Hz}$ & $2792 \mathrm{~Hz}$ & $2337 \mathrm{~Hz}$ & $2337 \mathrm{~Hz}$ \\
5 & $1671 \mathrm{~Hz}$ & $2022 \mathrm{~Hz}$ & $1951 \mathrm{~Hz}$ & $1671 \mathrm{~Hz}$ \\
7 & $1776 \mathrm{~Hz}$ & $1881 \mathrm{~Hz}$ & $1741 \mathrm{~Hz}$ & $1987 \mathrm{~Hz}$ \\
\hline
\end{tabular}

FONTE: Elaborado pelas autoras.

A transição formântica ao fim do som fricativo e ao início da vogal são também pistas que podem contribuir para a detecção do ponto de articulação das fricativas. Para tanto, analisamos os valores do início dos formantes das vogais subsequentes aos segmentos fricativos.

De acordo com a tabela 2, verificamos que os participantes apresentaram valores próximos referentes às medidas de F1 e maior variação nas medidas de F2 e F3. 
TABELA 2 - VALORES MÉDIOS DO INÍCIO DA FREQUÊNCIA DOS FORMANTES DA VOGAL SEGUINTE NA PALAVRA RZEKA

\begin{tabular}{c|c|c|c}
\hline \multicolumn{1}{c}{ Inf. } & F1 & F2 & F3 \\
\hline 1 & $523 \mathrm{~Hz}$ & $1863 \mathrm{~Hz}$ & $2853 \mathrm{~Hz}$ \\
2 & $426 \mathrm{~Hz}$ & $1951 \mathrm{~Hz}$ & $2888 \mathrm{~Hz}$ \\
6 & $435 \mathrm{~Hz}$ & $1819 \mathrm{~Hz}$ & $2826 \mathrm{~Hz}$ \\
8 & $540 \mathrm{~Hz}$ & $2215 \mathrm{~Hz}$ & $2818 \mathrm{~Hz}$ \\
\hline 3 & $330 \mathrm{~Hz}$ & $1426 \mathrm{~Hz}$ & $2433 \mathrm{~Hz}$ \\
4 & $364 \mathrm{~Hz}$ & $1481 \mathrm{~Hz}$ & $2582 \mathrm{~Hz}$ \\
5 & $382 \mathrm{~Hz}$ & $1719 \mathrm{~Hz}$ & $2319 \mathrm{~Hz}$ \\
7 & $523 \mathrm{~Hz}$ & $1461 \mathrm{~Hz}$ & $2319 \mathrm{~Hz}$ \\
\hline
\end{tabular}

FONTE: Elaborado pelas autoras.

Conforme Halle e Stevens (1997), os valores médios de F1 na transição inicial da retroflexa para a vogal ficam acima de $460 \mathrm{~Hz}$. Ao passo que os valores de F2 ocorrem aproximadamente a partir de $1250 \mathrm{~Hz}$, já os valores de F3 ficam em torno de $2360 \mathrm{~Hz}$.

Alguns autores mencionam que a retroflexão pode ser vista na transição inicial da fricativa para a vogal em função das medidas mais baixas do F2. Sendo assim, os Informantes 3, 4 e 7 possivelmente fizeram mais retroflexão, pois verificamos que os valores para F2 e F3 são mais baixos.

\section{FIGURA 5 - REALIZAÇÃO DA FRICATIVA [3] NA PALAVRA RZEKA [‘3عka] PELA INFORMANTE 1}

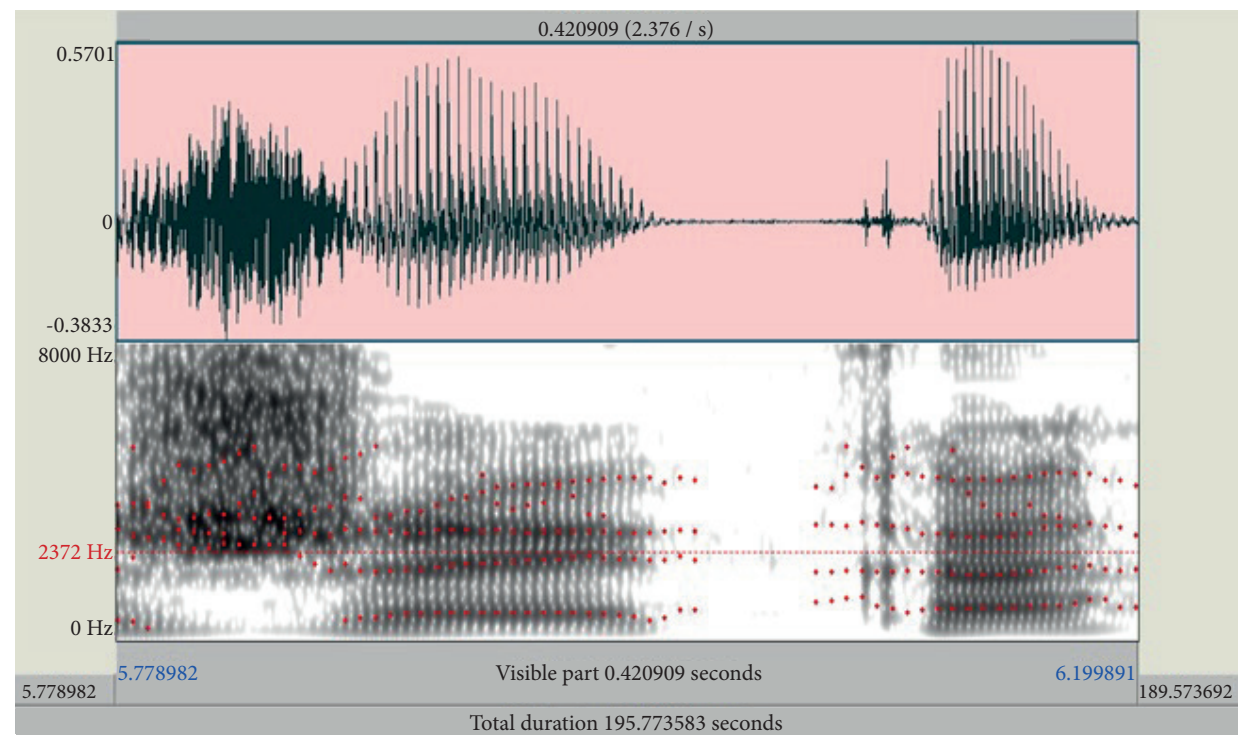

FONTE: Elaborado pelas autoras. 
Apresentamos os resultados para os dados de życie, para a fricativa [3] na tabela 3. Nos dados dos Informantes 2, 3, 5, 7 para todas as produções, o ruído de frequência iniciou abaixo de $2000 \mathrm{~Hz}$, já para os Informantes 4 e 8 os valores oscilaram e, em algumas realizações, nota-se uma frequência acima de $2000 \mathrm{~Hz}$. A Informante 1, por outro lado, realizou, para todas as produções, uma pós-alveolar com valores acima de $2000 \mathrm{~Hz}$. Neste dado, observamos que, na maioria das repetições, os informantes produziram uma fricativa retroflexa, semelhante nos dados de rzeka. A figura 6 apresenta a produção da fricativa pós-alveolar.

TABELA 3 - VALORES DO INÍCIO DA FREQUÊNCIA DE RUÍDO NOS DADOS DE $\dot{Z} Y C I E$

\begin{tabular}{ccccc}
\hline Inf. & Repetição 1 & Repetição 2 & Repetição 3 & Repetição 4 \\
\hline 1 & $2232 \mathrm{~Hz}$ & $2092 \mathrm{~Hz}$ & $2337 \mathrm{~Hz}$ & $2302 \mathrm{~Hz}$ \\
2 & $1776 \mathrm{~Hz}$ & $1706 \mathrm{~Hz}$ & $1776 \mathrm{~Hz}$ & $1811 \mathrm{~Hz}$ \\
6 & $1846 \mathrm{~Hz}$ & $1706 \mathrm{~Hz}$ & $1706 \mathrm{~Hz}$ & $1601 \mathrm{~Hz}$ \\
8 & $1951 \mathrm{~Hz}$ & $2232 \mathrm{~Hz}$ & $1881 \mathrm{~Hz}$ & $1811 \mathrm{~Hz}$ \\
\hline 3 & $1811 \mathrm{~Hz}$ & $1741 \mathrm{~Hz}$ & $1566 \mathrm{~Hz}$ & $1601 \mathrm{~Hz}$ \\
4 & $1798 \mathrm{~Hz}$ & $2057 \mathrm{~Hz}$ & $2162 \mathrm{~Hz}$ & $1951 \mathrm{~Hz}$ \\
5 & $1286 \mathrm{~Hz}$ & $1531 \mathrm{~Hz}$ & $1426 \mathrm{~Hz}$ & $1496 \mathrm{~Hz}$ \\
7 & $1636 \mathrm{~Hz}$ & $1566 \mathrm{~Hz}$ & $1601 \mathrm{~Hz}$ & $1671 \mathrm{~Hz}$ \\
\hline
\end{tabular}

FONTE: Elaborado pelas autoras.

\section{FIGURA 6 - PRODUÇÃO DO VOCÁBULO ŻYCIE ['3itce] PELA INFORMANTE 8}

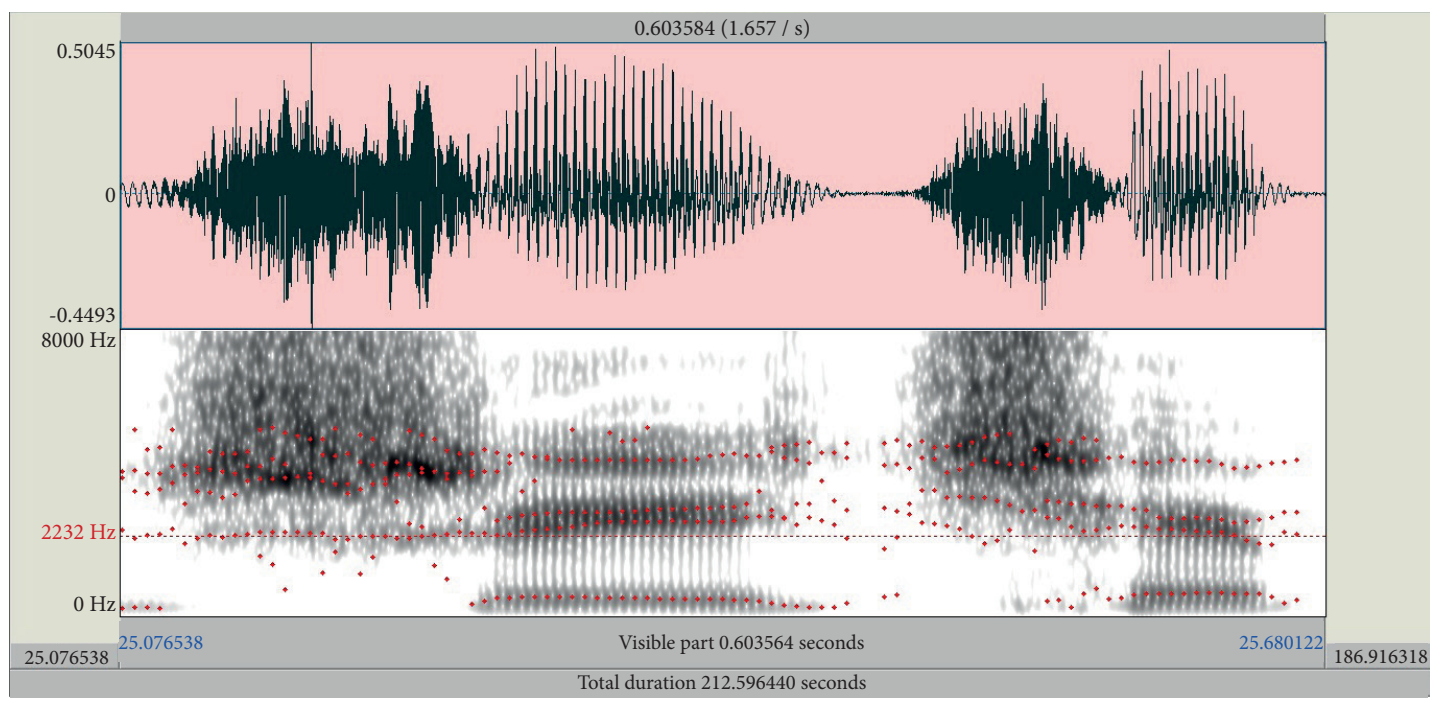

FONTE: Elaborado pelas autoras. 
Na tabela 4, ilustramos as medidas da transição formântica referente ao dado życie ['jitcع]. Notamos que a média dos valores de F2 para o fim do som fricativo e o início da vogal são muito próximas entre os informantes, abaixo de $2000 \mathrm{~Hz}$, com exceção das Informantes 1 e 8, que mostram valores superiores a $2000 \mathrm{~Hz}$. Os valores de F2 dos Informantes 4 e 5 foram os mais baixos, o que podem evidenciar retroflexão também.

TABELA 4 - MÉDIA DOS VALORES DO INÍCIO DA FREQUÊNCIA DOS FORMANTES DA VOGAL [i] QUE SEGUE A FRICATIVA NA PALAVRA ŻYCIE [' 3 it $6 \varepsilon]$

\begin{tabular}{cccc}
\hline Inf. & F1 & F2 & F3 \\
\hline 1 & $444 \mathrm{~Hz}$ & $2144 \mathrm{~Hz}$ & $2950 \mathrm{~Hz}$ \\
2 & $356 \mathrm{~Hz}$ & $1889 \mathrm{~Hz}$ & $2827 \mathrm{~Hz}$ \\
6 & $409 \mathrm{~Hz}$ & $1890 \mathrm{~Hz}$ & $2695 \mathrm{~Hz}$ \\
8 & $444 \mathrm{~Hz}$ & $2249 \mathrm{~Hz}$ & $2349 \mathrm{~Hz}$ \\
\hline 3 & $356 \mathrm{~Hz}$ & $1872 \mathrm{~Hz}$ & $2704 \mathrm{~Hz}$ \\
4 & $330 \mathrm{~Hz}$ & $1688 \mathrm{~Hz}$ & $2494 \mathrm{~Hz}$ \\
5 & $417 \mathrm{~Hz}$ & $1672 \mathrm{~Hz}$ & $2337 \mathrm{~Hz}$ \\
7 & $391 \mathrm{~Hz}$ & $1811 \mathrm{~Hz}$ & $2319 \mathrm{~Hz}$ \\
\hline
\end{tabular}

FONTE: Elaborado pelas autoras.

Nos dados de żaba ['3aba], constatamos também uma variação no que diz respeito à fricativa inicial, semelhante aos vocábulos rzeka e życie. A maioria das produções se referem à fricativa retroflexa seguindo os parâmetros das medidas do início do ruído do som fricativo. A figura 7 corresponde a uma pós-alveolar.

TABELA 5 - VALORES DO COMEÇO DA FREQUÊNCIA DE RUÍDO NOS DADOS DE $\dot{Z} A B A[$ '3aba]

\begin{tabular}{ccccc}
\hline Inf. & Repetição 1 & Repetição 2 & Repetição 3 & Repetição 4 \\
\hline 1 & $2092 \mathrm{~Hz}$ & $2022 \mathrm{~Hz}$ & $2302 \mathrm{~Hz}$ & $2022 \mathrm{~Hz}$ \\
2 & $2197 \mathrm{~Hz}$ & $1811 \mathrm{~Hz}$ & $1636 \mathrm{~Hz}$ & $1531 \mathrm{~Hz}$ \\
6 & $1776 \mathrm{~Hz}$ & $1636 \mathrm{~Hz}$ & $1706 \mathrm{~Hz}$ & $1741 \mathrm{~Hz}$ \\
8 & $1776 \mathrm{~Hz}$ & $1601 \mathrm{~Hz}$ & $1951 \mathrm{~Hz}$ & $2022 \mathrm{~Hz}$ \\
\hline 3 & $1601 \mathrm{~Hz}$ & $1706 \mathrm{~Hz}$ & $1916 \mathrm{~Hz}$ & $1776 \mathrm{~Hz}$ \\
4 & $1972 \mathrm{~Hz}$ & $1987 \mathrm{~Hz}$ & $2057 \mathrm{~Hz}$ & $2057 \mathrm{~Hz}$ \\
5 & $1531 \mathrm{~Hz}$ & $1496 \mathrm{~Hz}$ & $1216 \mathrm{~Hz}$ & $1356 \mathrm{~Hz}$ \\
7 & $1146 \mathrm{~Hz}$ & $1251 \mathrm{~Hz}$ & $1551 \mathrm{~Hz}$ & $1601 \mathrm{~Hz}$ \\
\hline
\end{tabular}

FONTE: Elaborado pelas autoras. 


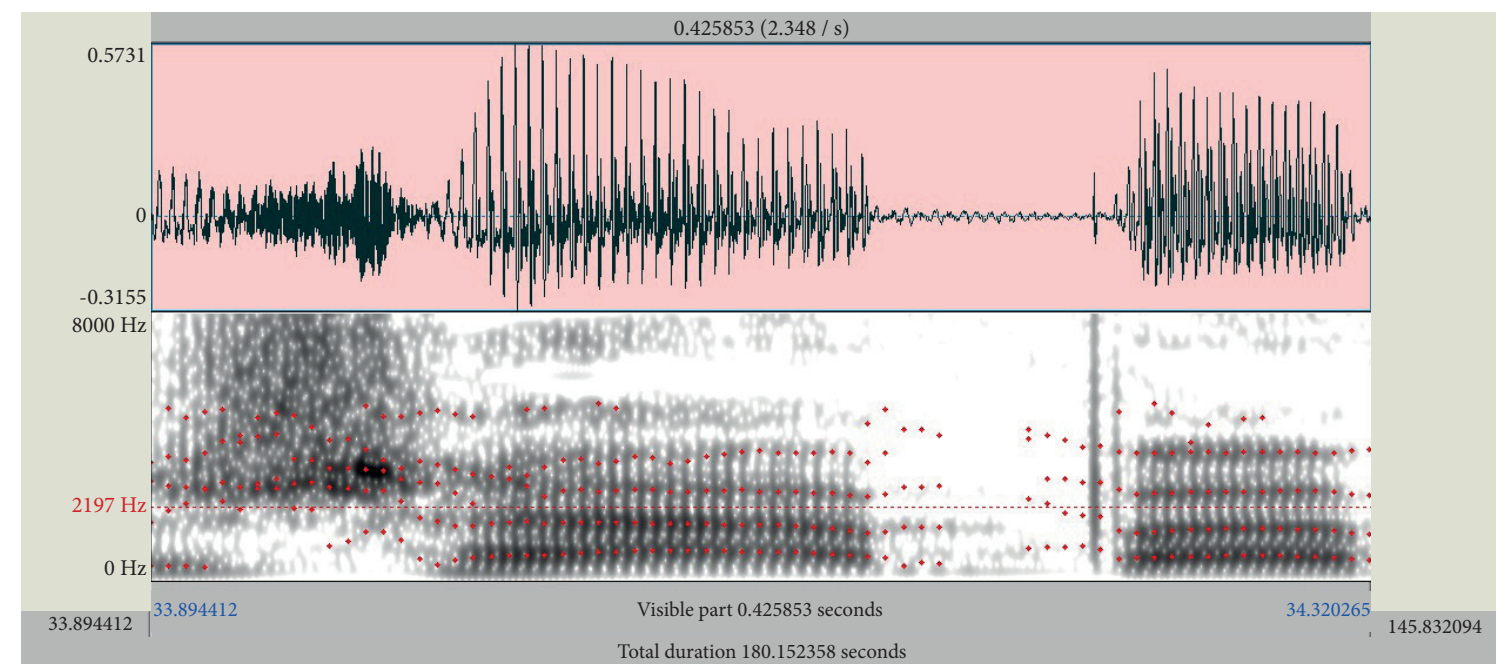

FONTE: Elaborado pelas autoras.

No entanto, as medidas da transição formântica entre os informantes são muito próximas, principalmente em $\mathrm{F} 1$ e F2, conforme a tabela 6 . O que pode evidenciar uma articulação semelhante na produção dessa fricativa. Ainda percebemos que valores de F2 dos Informantes 3, 4 e 5 foram os mais baixos do grupo, evidenciando assim, possivelmente, uma retroflexão.

TABELA 6 - MÉDIA DOS VALORES DO INÍCIO DA FREQUÊNCIA DOS FORMANTES DA VOGAL [a] QUE SEGUE A FRICATIVA NA PALAVRA ŻABA ['3aba]

\begin{tabular}{c|c|c|c}
\hline \multicolumn{1}{c}{ Inf. } & F1 & F2 & F3 \\
\hline 1 & $597 \mathrm{~Hz}$ & $1667 \mathrm{~Hz}$ & $2831 \mathrm{~Hz}$ \\
2 & $558 \mathrm{~Hz}$ & $1697 \mathrm{~Hz}$ & $2649 \mathrm{~Hz}$ \\
6 & $414 \mathrm{~Hz}$ & $1551 \mathrm{~Hz}$ & $2580 \mathrm{~Hz}$ \\
8 & $523 \mathrm{~Hz}$ & $1890 \mathrm{~Hz}$ & $2532 \mathrm{~Hz}$ \\
3 & $549 \mathrm{~Hz}$ & $1364 \mathrm{~Hz}$ & $2582 \mathrm{~Hz}$ \\
4 & $558 \mathrm{~Hz}$ & $1304 \mathrm{~Hz}$ & $2694 \mathrm{~Hz}$ \\
5 & $532 \mathrm{~Hz}$ & $1399 \mathrm{~Hz}$ & $2196 \mathrm{~Hz}$ \\
7 & $523 \mathrm{~Hz}$ & $1557 \mathrm{~Hz}$ & $2319 \mathrm{~Hz}$ \\
\hline
\end{tabular}

FONTE: Elaborado pelas autoras. 
O português não possui fricativas alvéolo-palatais, enquanto, no polonês elas são produtivas. Na tabela 7, visualizamos os valores para o início da frequência de ruído para fricativa alvéolo-palatal vozeada. Notamos que há uma variabilidade nas produções. As Informantes 1, 2, 6 e 8 realizaram a fricativa com valores do começo do ruído acima de $2000 \mathrm{~Hz}$. Já os Informantes do sexo masculino abaixo de $2000 \mathrm{~Hz}$. Ladefoged e Disner (2012) mostram que, na fricativa alvéolo-palatal, é possível visualizar o pico um pouco acima de $2000 \mathrm{~Hz}$. Com isso, podemos dizer que as realizações das Informantes do sexo feminino demonstram a produção de uma alvéolo-palatal. No que se refere ao sexo masculino, alguns autores chamam a atenção para o início da frequência do ruído que, para os homens, é diferente das mulheres. Para confirmamos essa hipótese, seria necessário analisar mais dados da fricativa alvéolo-palatal vozeada. Na figura 8 , observamos a produção da fricativa alvéolo-palatal pela Informante 2 .

\section{TABELA 7: VALORES DO INÍCIO DA FREQUÊNCIA DE RUÍDO NOS DADOS DE ZIELONY ${ }^{5}$}

\begin{tabular}{ccccc}
\hline Inf. & Repetição 1 & Repetição 2 & Repetição 3 & Repetição 4 \\
\hline 1 & $2126 \mathrm{~Hz}$ & $2022 \mathrm{~Hz}$ & $2127 \mathrm{~Hz}$ & $2057 \mathrm{~Hz}$ \\
2 & $2223 \mathrm{~Hz}$ & $2232 \mathrm{~Hz}$ & $2232 \mathrm{~Hz}$ & $2267 \mathrm{~Hz}$ \\
6 & $2092 \mathrm{~Hz}$ & $2092 \mathrm{~Hz}$ & $2127 \mathrm{~Hz}$ & $2092 \mathrm{~Hz}$ \\
8 & $2512 \mathrm{~Hz}$ & $2337 \mathrm{~Hz}$ & - & $2407 \mathrm{~Hz}$ \\
\hline 3 & $1774 \mathrm{~Hz}$ & $1846 \mathrm{~Hz}$ & $1916 \mathrm{~Hz}$ & $1881 \mathrm{~Hz}$ \\
4 & $1739 \mathrm{~Hz}$ & $1741 \mathrm{~Hz}$ & $1811 \mathrm{~Hz}$ & $1811 \mathrm{~Hz}$ \\
5 & $1710 \mathrm{~Hz}$ & $1811 \mathrm{~Hz}$ & $1916 \mathrm{~Hz}$ & $1846 \mathrm{~Hz}$ \\
7 & $1671 \mathrm{~Hz}$ & $1951 \mathrm{~Hz}$ & $1846 \mathrm{~Hz}$ & $1951 \mathrm{~Hz}$ \\
\hline
\end{tabular}

FONTE: Elaborado pelas autoras.

\footnotetext{
${ }^{5}$ Alguns informantes não produziram a palavra-alvo de estudo. Esses dados foram identificados nas tabelas pelo símbolo - .
} 
FIGURA 8 - PRODUÇÃO DA FRICATIVA ALVÉOLO-PALATAL EM ZIELONY [z๕’loni] PELA INFORMANTE 2

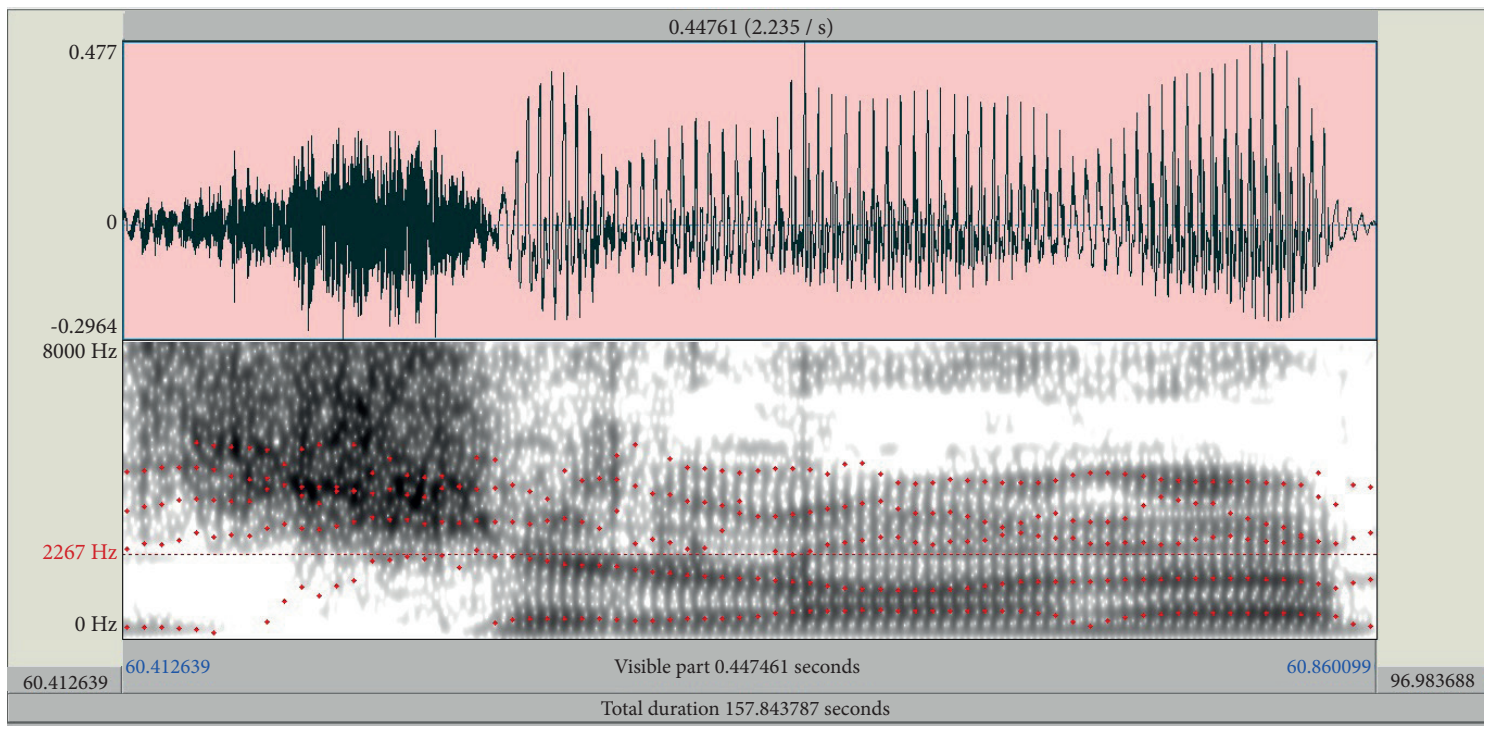

FONTE: Elaborado pelas autoras.

$\mathrm{Na}$ tabela 8, podemos verificar que, à exceção da Informante 8 , os demais informantes apresentaram valores próximos, principalmente, referentes às medidas de F1 e F2. A Informante 8, a mais velha do grupo, mostrou medidas superiores. De acordo com esse parâmetro, podemos evidenciar que o ponto de articulação da fricativa foi semelhante entre os participantes. No entanto, se levarmos em conta que a menor medida de F2 representa retroflexão, podemos observar que as produções dos Informantes 3, 4, 5 e 7 apresentaram valores mais baixos.

TABELA 8 - MÉDIA DOS VALORES DO INÍCIO DA FREQUÊNCIA DOS FORMANTES DA VOGAL SUBSEQUENTE NO DADO ZIELONY

\begin{tabular}{c|c|c|c}
\hline \multicolumn{1}{c}{ Inf. } & F1 & F2 & F3 \\
\hline 1 & $382 \mathrm{~Hz}$ & $2197 \mathrm{~Hz}$ & $3011 \mathrm{~Hz}$ \\
2 & $365 \mathrm{~Hz}$ & $2039 \mathrm{~Hz}$ & $2995 \mathrm{~Hz}$ \\
6 & $365 \mathrm{~Hz}$ & $1954 \mathrm{~Hz}$ & $2967 \mathrm{~Hz}$ \\
8 & $409 \mathrm{~Hz}$ & $2652 \mathrm{~Hz}$ & $3020 \mathrm{~Hz}$ \\
\hline 3 & $339 \mathrm{~Hz}$ & $1837 \mathrm{~Hz}$ & $2590 \mathrm{~Hz}$ \\
4 & $339 \mathrm{~Hz}$ & $1707 \mathrm{~Hz}$ & $2555 \mathrm{~Hz}$ \\
5 & $362 \mathrm{~Hz}$ & $1881 \mathrm{~Hz}$ & $2488 \mathrm{~Hz}$ \\
7 & $391 \mathrm{~Hz}$ & $1863 \mathrm{~Hz}$ & $2503 \mathrm{~Hz}$ \\
\hline
\end{tabular}

FONTE: Elaborado pelas autoras. 
Agora passamos para a descrição da fricativa pós-alveolar não vozeada nos dados de szkoła, szkło e sześć. Na tabela 9, observamos os dados de szkoła. Percebemos que, nas produções das Informantes 1 e 2, o valor do início do ruído de frequência aparece acima de $2000 \mathrm{~Hz}$, e, no caso da Informante 1, chegando quase a $3000 \mathrm{~Hz}$. O Informante 3 se aproximou de $2000 \mathrm{~Hz}$, como também na primeira repetição produziu acima. Os demais falantes, no entanto, apresentaram valores abaixo de $2000 \mathrm{~Hz}$. Esses valores indicam que, semelhante aos dados de rzeka, życie e żaba, os falantes alternaram entre uma pósalveolar e uma retroflexa. A figura 9 mostra a realização da fricativa retroflexa.

TABELA 9 - VALORES DO INÍCIO DA FREQUÊNCIA DE RUÍDO NOS DADOS DE SZKOLA ['Jkowa]

\begin{tabular}{c|c|c|c|c}
\hline \multicolumn{1}{c}{ Inf. } & \multicolumn{1}{c}{ Repetição 1 } & \multicolumn{1}{c}{ Repetição 2 } & \multicolumn{1}{c}{ Repetição 3 } & Repetição 4 \\
\hline 1 & $2407 \mathrm{~Hz}$ & $2968 \mathrm{~Hz}$ & $2442 \mathrm{~Hz}$ & $2933 \mathrm{~Hz}$ \\
2 & $2127 \mathrm{~Hz}$ & $2057 \mathrm{~Hz}$ & $2127 \mathrm{~Hz}$ & $2057 \mathrm{~Hz}$ \\
6 & $1551 \mathrm{~Hz}$ & $1706 \mathrm{~Hz}$ & $1426 \mathrm{~Hz}$ & $1601 \mathrm{~Hz}$ \\
8 & $1706 \mathrm{~Hz}$ & $1951 \mathrm{~Hz}$ & $1987 \mathrm{~Hz}$ & $1531 \mathrm{~Hz}$ \\
\hline 3 & $2022 \mathrm{~Hz}$ & $1881 \mathrm{~Hz}$ & $1916 \mathrm{~Hz}$ & $1881 \mathrm{~Hz}$ \\
4 & $1566 \mathrm{~Hz}$ & $1426 \mathrm{~Hz}$ & $1636 \mathrm{~Hz}$ & $1706 \mathrm{~Hz}$ \\
5 & $1391 \mathrm{~Hz}$ & $1706 \mathrm{~Hz}$ & $1636 \mathrm{~Hz}$ & $1496 \mathrm{~Hz}$ \\
7 & $1461 \mathrm{~Hz}$ & $1496 \mathrm{~Hz}$ & $1741 \mathrm{~Hz}$ & $1776 \mathrm{~Hz}$ \\
\hline
\end{tabular}

FONTE: Elaborado pelas autoras. 
FIGURA 9 - PRODUÇÃO DA FRICATIVA NO VOCÁBULO SZKOŁA [‘fkəwa] PELA INFORMANTE 6

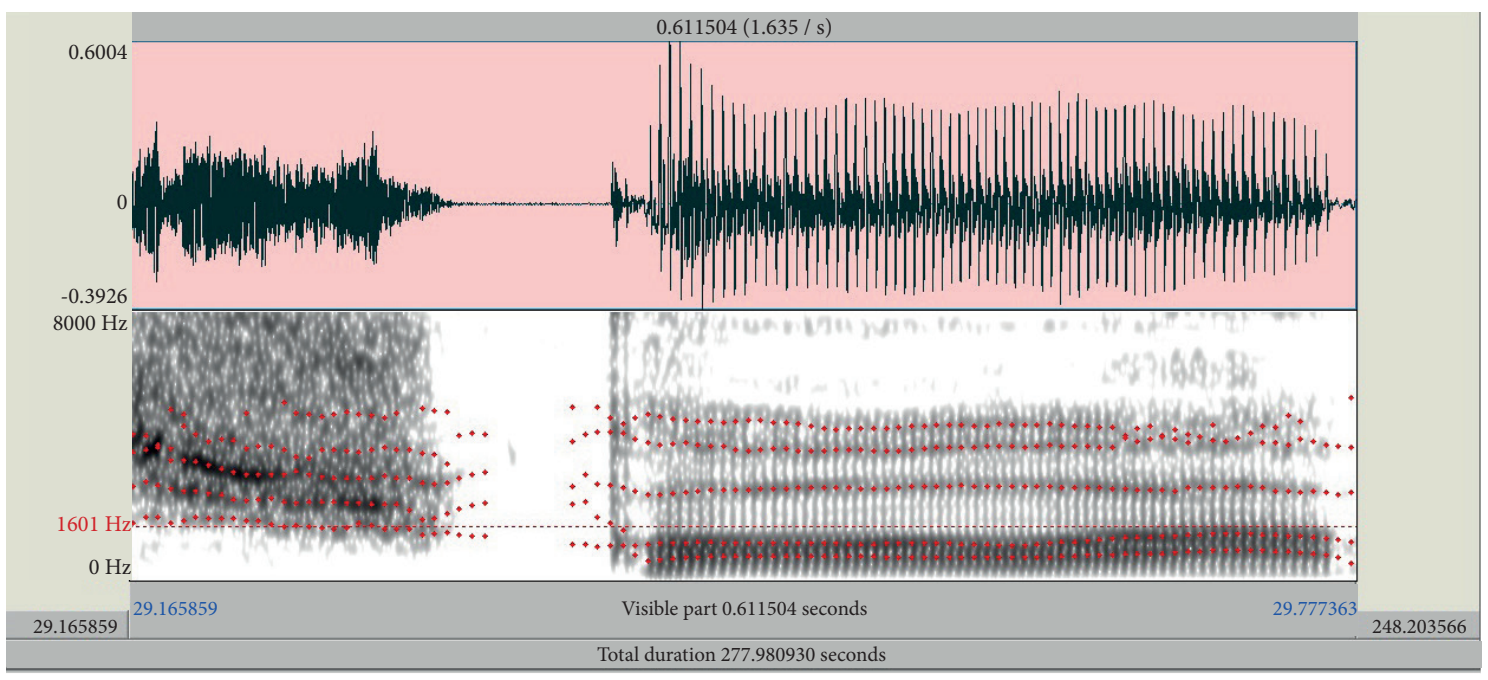

FONTE: Elaborado pelas autoras.

Na tabela 10, são exibidos os valores para os dados de szkło, evidenciando a realização de uma fricativa retroflexa, conforme figura 9. Já a tabela 11 mostra as produções de sześć, alternando entre pós-alveolar e retroflexa. Na figura 10, visualizamos a produção da fricativa pós- alveolar.

TABELA 10 - VALORES DO INÍCIO DA FREQUÊNCIA DE RUÍDO NOS DADOS DE $S Z K E O\left[^{\circ} \mathrm{j} \mathrm{kw}\right]^{6}$

\begin{tabular}{ccccc}
\hline Inf. & Repetição 1 & Repetição 2 & Repetição 3 & Repetição 4 \\
\hline 1 & $1987 \mathrm{~Hz}$ & $1776 \mathrm{~Hz}$ & $1916 \mathrm{~Hz}$ & $1951 \mathrm{~Hz}$ \\
2 & $1881 \mathrm{~Hz}$ & - & $1741 \mathrm{~Hz}$ & $1914 \mathrm{~Hz}$ \\
6 & $1776 \mathrm{~Hz}$ & $1707 \mathrm{~Hz}$ & $1776 \mathrm{~Hz}$ & $1741 \mathrm{~Hz}$ \\
8 & $1776 \mathrm{~Hz}$ & $1636 \mathrm{~Hz}$ & $1426 \mathrm{~Hz}$ & $1321 \mathrm{~Hz}$ \\
\hline 3 & $1741 \mathrm{~Hz}$ & $1426 \mathrm{~Hz}$ & $1319 \mathrm{~Hz}$ & $1636 \mathrm{~Hz}$ \\
4 & $1418 \mathrm{~Hz}$ & $1461 \mathrm{~Hz}$ & $1391 \mathrm{~Hz}$ & $1426 \mathrm{~Hz}$ \\
5 & $1274 \mathrm{~Hz}$ & $1416 \mathrm{~Hz}$ & $1601 \mathrm{~Hz}$ & $1321 \mathrm{~Hz}$ \\
7 & $1601 \mathrm{~Hz}$ & $1741 \mathrm{~Hz}$ & $1601 \mathrm{~Hz}$ & $1356 \mathrm{~Hz}$ \\
\hline
\end{tabular}

FONTE: Elaborado pelas autoras.

\footnotetext{
${ }^{6}$ Alguns informantes não produziram a palavra-alvo de estudo. Esses dados foram identificados nas tabelas pelo símbolo -.
} 
FIGURA 10 - PRODUÇÃO DA FRICATIVA PÓS-ALVEOLAR [J] NO VOCÁBULO SZKŁO ['Jkwo] PELO INFORMANTE 7

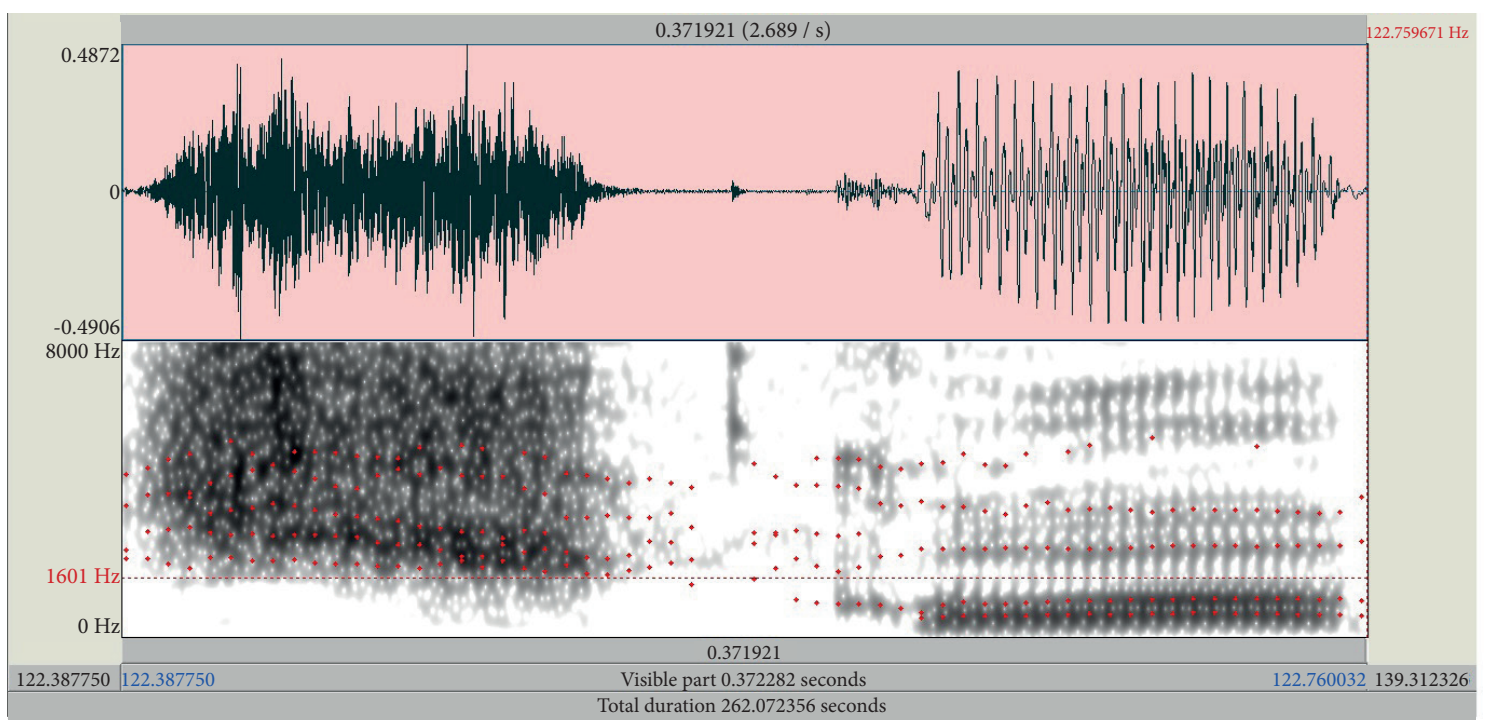

FONTE: Elaborado pelas autoras.

TABELA 11 - VALORES DO INÍCIO DA FREQUÊNCIA DE RUÍDO NOS DADOS DE SZEŚĆ

\begin{tabular}{c|c|c|c|c}
\hline \multicolumn{1}{c}{ Inf. } & \multicolumn{1}{c}{ Repetição 1 } & \multicolumn{1}{c}{ Repetição 2 } & \multicolumn{1}{c}{ Repetição 3 } & Repetição 4 \\
\hline 1 & $2161 \mathrm{~Hz}$ & $2022 \mathrm{~Hz}$ & $2127 \mathrm{~Hz}$ & $2092 \mathrm{~Hz}$ \\
2 & $2197 \mathrm{~Hz}$ & $1811 \mathrm{~Hz}$ & $1916 \mathrm{~Hz}$ & $1706 \mathrm{~Hz}$ \\
6 & $1741 \mathrm{~Hz}$ & $1706 \mathrm{~Hz}$ & $1811 \mathrm{~Hz}$ & $1706 \mathrm{~Hz}$ \\
8 & $1987 \mathrm{~Hz}$ & $2092 \mathrm{~Hz}$ & $2022 \mathrm{~Hz}$ & $2057 \mathrm{~Hz}$ \\
\hline 3 & $1531 \mathrm{~Hz}$ & $1601 \mathrm{~Hz}$ & $1426 \mathrm{~Hz}$ & $1461 \mathrm{~Hz}$ \\
4 & $1274 \mathrm{~Hz}$ & $1426 \mathrm{~Hz}$ & $1531 \mathrm{~Hz}$ & $1671 \mathrm{~Hz}$ \\
5 & $1321 \mathrm{~Hz}$ & $1356 \mathrm{~Hz}$ & $1531 \mathrm{~Hz}$ & $1636 \mathrm{~Hz}$ \\
7 & $1216 \mathrm{~Hz}$ & $1391 \mathrm{~Hz}$ & $1321 \mathrm{~Hz}$ & $1286 \mathrm{~Hz}$ \\
\hline
\end{tabular}

FONTE: Elaborado pelas autoras. 


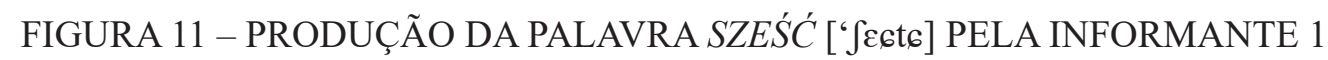

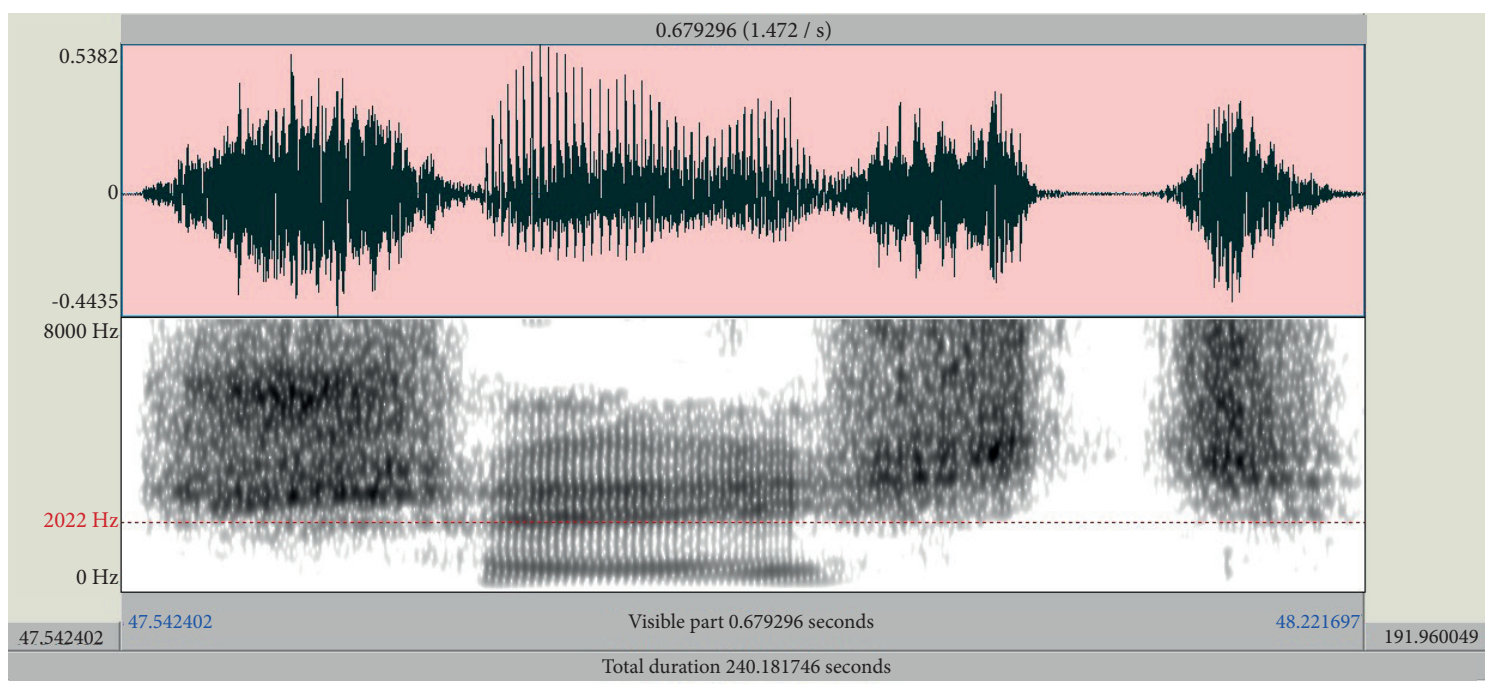

FONTE: Elaborado pelas autoras.

Na tabela 12, ilustramos os valores da transição formântica para o dado sześć, cujas medidas de F1 e F2, observamos, são muito próximas entre os participantes. Notamos que a Informante 1, a mais nova do grupo, e a Informante 8, a mais velha, apresentaram valores bem acima dos demais. Conforme esse parâmetro, também podemos deduzir que o ponto de articulação dessa fricativa foi similar para a maioria do grupo. Entretanto, levando em consideração que os valores mais baixos de F2 podem estar relacionados à retroflexão, verificamos esse comportamento nos Informantes 3, 4, 5 e 6.

TABELA 12 - MÉDIA DOS VALORES DO INÍCIO DA FREQUÊNCIA DOS FORMANTES DA VOGAL SUBSEQUENTE NO DADO SZEŚĆ

\begin{tabular}{c|c|c|c}
\hline \multicolumn{1}{c}{ Inf. } & F1 & F2 & F3 \\
\hline 1 & $575 \mathrm{~Hz}$ & $1838 \mathrm{~Hz}$ & $2871 \mathrm{~Hz}$ \\
2 & $585 \mathrm{~Hz}$ & $1749 \mathrm{~Hz}$ & $2730 \mathrm{~Hz}$ \\
6 & $490 \mathrm{~Hz}$ & $1584 \mathrm{~Hz}$ & $2473 \mathrm{~Hz}$ \\
8 & $549 \mathrm{~Hz}$ & $2217 \mathrm{~Hz}$ & $2687 \mathrm{~Hz}$ \\
\hline 3 & $487 \mathrm{~Hz}$ & $1469 \mathrm{~Hz}$ & $2442 \mathrm{~Hz}$ \\
4 & $479 \mathrm{~Hz}$ & $1417 \mathrm{~Hz}$ & $2520 \mathrm{~Hz}$ \\
5 & $646 \mathrm{~Hz}$ & $1487 \mathrm{~Hz}$ & $2127 \mathrm{~Hz}$ \\
7 & $514 \mathrm{~Hz}$ & $1668 \mathrm{~Hz}$ & $2162 \mathrm{~Hz}$ \\
\hline
\end{tabular}

FONTE: Elaborado pelas autoras. 
Vejamos as tabelas 13 e 14, com informações quanto à produção da alvéolo-palatal nos dados de świat e śmietana pelos oito informantes, nas quatro repetições. Nessas produções, verificamos também uma variabilidade entre os falantes. Alguns produziram uma alvéolo-palatal, cujo valor é um pouco acima de $2000 \mathrm{~Hz}$ e outros como retroflexa. Na figura 12, visualizamos a fricativa alvéolo-palatal e, na figura 13, a retroflexa.

\section{TABELA 13: VALORES DO INÍCIO DA FREQUÊNCIA DE RUÍDO NOS DADOS DE SWIAT ${ }^{7}$}

\begin{tabular}{ccccc}
\hline Inf. & Repetição 1 & Repetição 2 & Repetição 3 & Repetição 4 \\
\hline 1 & $2022 \mathrm{~Hz}$ & $1846 \mathrm{~Hz}$ & $1987 \mathrm{~Hz}$ & $1987 \mathrm{~Hz}$ \\
2 & - & - & - & - \\
6 & $1951 \mathrm{~Hz}$ & $2232 \mathrm{~Hz}$ & $1916 \mathrm{~Hz}$ & $1846 \mathrm{~Hz}$ \\
8 & $2092 \mathrm{~Hz}$ & $1987 \mathrm{~Hz}$ & $2022 \mathrm{~Hz}$ & $2337 \mathrm{~Hz}$ \\
\hline 3 & $2195 \mathrm{~Hz}$ & $2512 \mathrm{~Hz}$ & $2162 \mathrm{~Hz}$ & $2302 \mathrm{~Hz}$ \\
4 & - & - & - & - \\
5 & $1507 \mathrm{~Hz}$ & $1636 \mathrm{~Hz}$ & $1636 \mathrm{~Hz}$ & $1601 \mathrm{~Hz}$ \\
7 & $1461 \mathrm{~Hz}$ & $1356 \mathrm{~Hz}$ & $1565 \mathrm{~Hz}$ & $1636 \mathrm{~Hz}$ \\
\hline
\end{tabular}

FONTE: Elaborado pelas autoras.

\section{FIGURA 12 - PRODUÇÃO DO VOCÁBULO ŚWIAT [“6f,jat] PELA INFORMANTE 1}

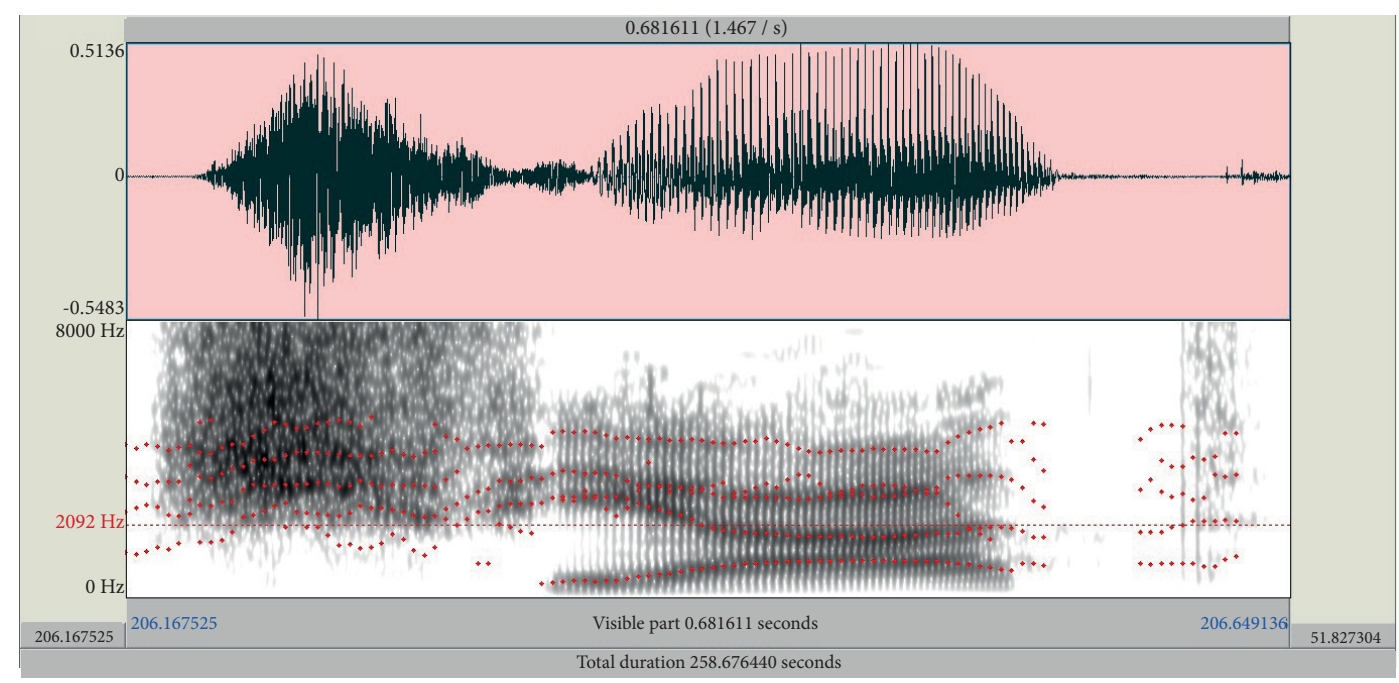

FONTE: Elaborado pelas autoras.

\footnotetext{
${ }^{7}$ Alguns informantes não produziram a palavra-alvo de estudo. Esses dados foram identificados nas tabelas pelo símbolo -.
} 
TABELA 14 - VALORES DO INÍCIO DA FREQUÊNCIA DE RUÍDO NOS DADOS DE ŚMIETANA ${ }^{8}$

\begin{tabular}{ccccc}
\hline Inf. & Repetição 1 & Repetição 2 & Repetição 3 & Repetição 4 \\
\hline 1 & - & - & - & - \\
2 & $1739 \mathrm{~Hz}$ & $2227 \mathrm{~Hz}$ & $2092 \mathrm{~Hz}$ & $1856 \mathrm{~Hz}$ \\
6 & $1916 \mathrm{~Hz}$ & $2092 \mathrm{~Hz}$ & $1916 \mathrm{~Hz}$ & $2092 \mathrm{~Hz}$ \\
8 & $2547 \mathrm{~Hz}$ & $2127 \mathrm{~Hz}$ & $2407 \mathrm{~Hz}$ & $2477 \mathrm{~Hz}$ \\
\hline 3 & $1987 \mathrm{~Hz}$ & $1951 \mathrm{~Hz}$ & $1636 \mathrm{~Hz}$ & $1741 \mathrm{~Hz}$ \\
4 & $1739 \mathrm{~Hz}$ & $1846 \mathrm{~Hz}$ & $1636 \mathrm{~Hz}$ & $1846 \mathrm{~Hz}$ \\
5 & - & $1776 \mathrm{~Hz}$ & - & - \\
7 & $1286 \mathrm{~Hz}$ & $1671 \mathrm{~Hz}$ & $1768 \mathrm{~Hz}$ & $1741 \mathrm{~Hz}$ \\
\hline
\end{tabular}

FONTE: Elaborado pelas autoras.

FIGURA 13 - PRODUÇÃO DA FRICATIVA EM ŚMIETANA COMO [șm,c'tana] PELA INFORMANTE 4

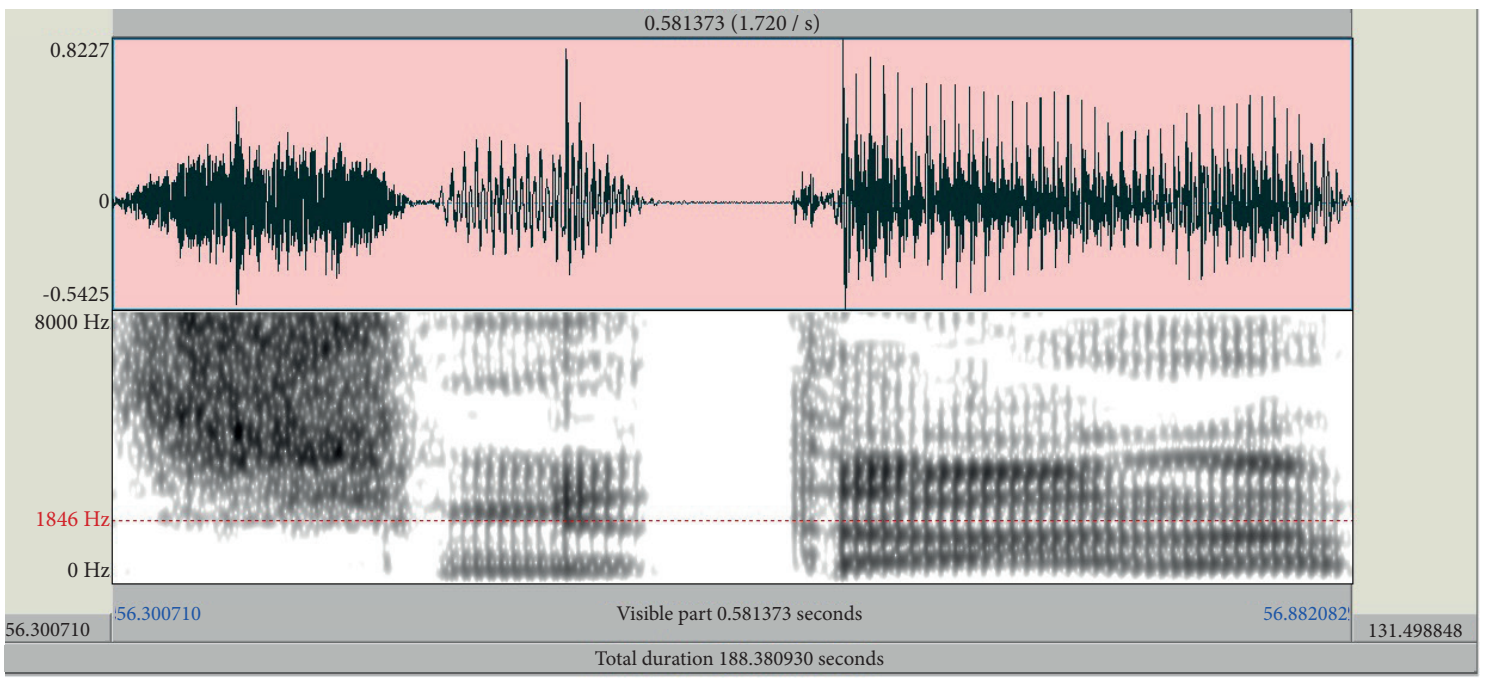

FONTE: Elaborado pelas autoras.

A análise do ponto de articulação dos sons fricativos, feita através da pista acústica de valor de frequência do início do ruído, mostrou então que nossos dados exibiram uma certa variabilidade na produção das fricativas pelos informantes. Essa variabilidade é

\footnotetext{
${ }^{8}$ Alguns informantes não produziram a palavra-alvo de estudo. Esses dados foram identificados nas tabelas pelo símbolo - .
} 
coerente com a literatura da área, pois uma questão relevante no que se refere à descrição das características acústicas das fricativas é a grande discrepância entre os espectros de uma fricativa por falantes diferentes (LADEFOGED; MADDIESON, 1996).

Adicionalmente, os valores formânticos na vogal adjacente também indicaram a produção de uma variante retroflexa principalmente pelos participantes do sexo masculino. Esse resultado precisa ser comprovado por estudos que apresentem mais dados e informantes, possibilitando, também, uma análise estatística.

\section{CONSIDERAÇÕES FINAIS}

O nosso estudo é descritivo, baseando-se na Teoria Acústica de Produção de Fala (KENT e READ, 1992), e aborda as características das fricativas na língua polonesa falada em Cruz Machado, mais especificamente na comunidade do Rio do Banho. Os moradores desse município de ascendência polonesa mantiveram a religiosidade, os costumes e a língua de seus antepassados, transmitindo-os aos seus filhos e netos. Essa peculiaridade é vista na quarta ou até quinta geração, cujos descendentes preservam o idioma e a identidade. A língua polonesa predomina no uso diário (trabalho na agricultura), reuniões familiares, entre os amigos e na igreja. Essa língua é falada nesse município há mais de cem anos e ainda é transmitida de geração em geração oralmente.

$\mathrm{Na}$ análise acústica das fricativas, os resultados apontam variação de ponto de articulação nas produções dos informantes. Para descrever o ponto de articulação dos sons fricativos no polonês falado em Cruz Machado, utilizamos as pistas acústicas do início da faixa de frequência do ruído e dos valores dos formantes vocálicos na transição entre os sons fricativos e a vogal subsequente.

Houve variabilidade em meio aos informantes e entre dados do mesmo participante para os valores de início da frequência do ruído fricativo, evidenciando realizações com pontos de articulação alvéolo-palatais, pós-alveolar e retroflexas. A análise dos dados sugere a presença de retroflexão nas fricativas produzidas pelos informantes, majoritariamente entre os participantes do sexo masculino e entre os mais jovens. Considerando a coarticulação entre os sons fricativos e vocálicos, o dado mais relevante nesta amostra foi $\dot{z} a b a$, no qual temos uma vogal mais próxima do ponto neutro e as medidas das duas pistas acústicas aqui observadas, o início da frequência do ruído fricativo, na maioria dos dados abaixo de $2000 \mathrm{~Hz}$, conforme a Tabela 5, e os valores formânticos da vogal adjacente ao som fricativo, com o F2 em torno de $1600 \mathrm{~Hz}$, conforme a Tabela 6, evidenciam a presença de retroflexão. 
A produção dos sons é variável devido a restrições articulatórias e às leis naturais da aerodinâmica e acústica que operam dentro do trato vocal (OHALA, 1983). No entanto, nem toda variação pode ser explicável em termos de considerações puramente fonéticas. Sendo assim, a distinção de ponto de articulação e a retroflexão das fricativas futuramente serão analisadas com outras pistas acústicas e tendo aporte de outras teorias e metodologias. Por exemplo, a variação sistemática tem sido estudada frequentemente em relação a fatores sociais como idade, sexo, classe social, etnia, dentre outros.

Neste texto, apresentamos detalhes fonéticos, por meio das pistas acústicas da faixa de início de ruído fricativo e dos valores formânticos da vogal adjacente, de algumas fricativas produzidas por falantes da língua polonesa em Cruz Machado, no interior do Paraná. Os dados demonstraram variabilidade de padrão entre os informantes e de produção em dados do mesmo participante, condicente com descrições para a produção dos sons fricativos na literatura da área, e presença de retroflexão nos sons fricativos condizente com as características do sistema da língua polonesa. Como perspectivas futuras, apontamos a necessidade de ampliação do corpus e a investigação de outras pistas acústicas para a descrição de pontos das fricativas no polonês falado no Paraná. 


\section{REFERÊNCIAS:}

NIEWIADOMSKI, S. Aspectos sonoros da lingua polonesa falada em Cruz Machado no Paraná. 2019. Dissertação (Mestrado em Letras) - Universidade Estadual do CentroOeste, Guarapuava.

BARBOSA, P. A.; MADUREIRA, S. Manual de Fonética Acústica. Editora Cortez, 2015.

BOERSNA, P.; WEENIK, D. PRAAT doing Phonetics by Computer. University of Amsterdam Versão praat5342_win32zip (2 March 2016).

COLLING, I. Análise da produção de consoantes fricativas por alunos brasileiros de polonês como língua estrangeira. Trabalho de Conclusão de Curso (Graduação em LetrasPolonês) - Setor de Ciências Humanas, Universidade Federal do Paraná, Curitiba, 2014.

DOGIL, G. Hissing and Hushing Fricatives: A Comment on non-anterior Spirants in Polish. Manuscript University of Stuttgart, 1990.

DŁUGOSZ, C. Dicionário de Polaco-Português/Português-Polaco. Porto: Editora Porto, 2000 .

FANT, G. Acoustic theory of speech production: with calculations based on X-ray studies of Russian articulations. The Hague, Paris: Mouton, 1970.

GUSSMANN, E. The phonology of Polish. New York: Oxford University Press, 2007.

HAMANN, S. Retroflex fricatives in Slavic Languages. Journal of the International Phonetic Association, v. 34 (1), p. 53-67, 2004.

HAMANN, S. Retroflexion and Retraction revised. In: HALL, T.A.; POMPINOMARSCHALL, B.; ROCHOŃ, M. (Org.) Papers on Phonetics and Phonology: The Articulation, Acoustics and Perception of Consonants. ZAS Papers in Linguistics 28, 2002, p. 13-26.

HALLE, M.; STEVENS, K. The postalveolar fricatives of Polish. In: KIRITANI, S.; HIROSE, H.; FUJISAKI, H. (Org.) Speech Production and Language. Berlin; New York: Mouton de Gruyter, 1997. p. 177-193.

HAUPT, C. As fricativas [s], [z], [J] e [3] do português brasileiro. Revista Estudos Lingüísticos XXXVI (1), janeiro-abril, p. 37-46, 2007.

HAUSER, I. Coarticulation with alveopalatal sibilants in Mandarin and Polish: Phonetics or phonology? Annual Meetings on Phonology, Washington, DC, 2019. 
JASSEM, W. Polish. Journal of the International Phonetic Association: Illustrations of the IPA, 33, p. 103-107, 2003.

JESUS, L. M. Analysis of Portuguese Fricative Consonants. Mini Thesis Department of Electronics and Computer Science, University of Southampton, 1999.

KEATING, P. Coronal places of articulation. In: PARADIS, C.; PRUNET, F. (Org.) The Special Status of Coronals: Internal and External Evidence. San Diego: Academic Press, 1991. p. 29-48.

KENT, R. D.; READ, C. Análise Acústica da fala. Tradução de Alexsandro Rodrigues Meireles. 1. ed. São Paulo: Cortez, 2015.

KENT, R. D.; READ, C. The acoustic analysis of speech. San Diego: Singular Publishing Group, 1992.

KUDELA, K. Spectral analysis of Polish fricative consonants. In: JASSEN, W. (Ed.). Speech Analysis and Synthesis. Warsaw: PAN, 1968. p. 93-188.

LADEFOGED, P.; DISNER, S. F. Vowels and consonants. 3. ed. Oxford: Wiley-Blackwell, 2012.

LADEFOGED, P.; JOHNSON, K. A Course in Phonetics. 6. ed. Boston, Massachusetts, Estados Unidos: Wadsworth, Cengage Learnin, 2011.

LADEFOGED, P.; MADDIESON, I. The Sounds of the World's Languages. Oxford: Blackwell, 1996.

OHALA, J. J. The origin of sound patterns in vocal tract constraints. In: MACNEILAGE, P. F. (Org.) The production of speech. New York: Springer, 1983. p. 189-216.

ORZEŁ-DEREŃ, K. Meandry wielokulturowości. Tożsamość dzieci i dorosłych w społeczeństwie wielokulturowym na przykładzie Polonii brazylijskiej w municypium Cruz Machado. Pedagogika Przedszkolna i Wczesnoszkolna, v. 2, n 4, p. 41-54, 2014.

PADGETT, J.; ZYGIS, M. The evolution of sibilants in Polish and Russian. Journal of Slavic Linguistics. v.15 (2), p. 291-324, 2007.

SHADLE, C. H. The acoustics of fricatives consonants. Cambridge, MA: MIT Press, 1985.

SILVA, T. C. Fonética e fonologia do português: roteiro de estudos e guia de exercícios. São Paulo: Contexto, 2007. 
STEVENS, K. Acoustic Phonetics. Cambridge, MA: MIT Press, 1998.

STEVENS, K. N.; KLATT, D. H. Studies of Acoustic Properties of Speech Sound. Massachusetts: Air Force Cambridge Research Laboratories, 1968.

TRASK, R. L. A Dictionary of Phonetics and Phonology. London: Routledge, 1996.

ZYGIS, M.; HAMANN, S. Perceptual and acoustic cues of Polish coronal fricatives. In: INTERNATIONAL CONGRESS OF PHONETICS SCIENCES, 15., 3-9 ago. 2003, Barcelona. Proceedings of the $15^{\text {th }}$ International Congress of Phonetics Sciences, Barcelona: [s.n.], 2003. p. 395-398. 